\title{
Technology Diffusion and Aggregate Dynamics
}

\author{
David Andolfatto \\ Department of Economics, \\ University of Waterloo \\ and \\ CREFE/UQAM \\ Glenn M. MacDonald \\ W. E. Simon Graduate School of Business Administration \\ and \\ Department of Economics, \\ University of Rochester; \\ Economics Research Center/NORC
}

January 1998

\begin{abstract}
This paper develops and analyzes a macroeconomic model in which aggregate growth and fluctuations arise from the discovery and diffusion of new technologies; there are no exogenous aggregate shocks. The temporal behavior of aggregates is driven by individuals' efforts to innovate and/or make use of others' innovations.

Parameters describing preferences, production possibilities and learning technologies are estimated using post-war U.S. data. The model delivers predicted aggregates that grow and fluctuate much like the data. The key features of post-war growth are explained by new technologies that differ in terms of the magnitude of their improvement over existing methods and the difficulty of acquiring them. The model implies a negative trend in technological dispersion, and that the generally lower growth witnessed during the last two decades is the result of new technologies offering comparatively minor or less broadly-applicable improvements.

Data on the growing and fluctuating share of engineering Ph.D.s support the model's technological interpretation of the growth facts, and data on patent applications and adult schooling are consistent with the notion that newer technologies are more specific and proprietary.
\end{abstract}

\footnotetext{
This paper modifies and updates "Endogenous Technological Change and Aggregate Fluctuations," presented at the Canadian Economics Association meetings, June 1991 (Kingston). Over the years, this paper has benefited from the comments and criticisms of numerous individuals, including Fisher Black, Jeff Campbell, Tom Cooley, Mick Devereaux, Jeremy Greenwood, Hugo Hopenhayn, Robbie Jones, Boyan Jovanovic, Samuel Kortum, and Gregor Smith. As well, we would like to thank three anonymous referees for their thoughtful and detailed comments. Financial support for this project was provided by the Social Sciences and Humanities Research Council of Canada (Andolfatto) and the John M. Olin Foundation (MacDonald).
} 
Technology Diffusion and Aggregate Dynamics

\section{Introduction}

This paper explores the quantitative properties of a dynamic general equilibrium model in which growth and fluctuations in aggregate income follow from the discovery and spread of new technological know-how. Growth occurs because better technologies are discovered and then widely used. Fluctuations occur because learning how to use new technology consumes resources, and attempts to learn - both innovation and imitation - divert resources away from production. Imitation plays a key role in generating economy-wide S-shaped patterns of diffusion of new technology; this diffusion generates corresponding fluctuations in aggregates. According to this view then, fluctuations in aggregate output are not "business cycles" in the sense of increasing and decreasing economic activity caused by serially-correlated productivity shocks, coordination failures or government policy. Instead, they are viewed simply as one dimension of the economy's observed behavior as its wealth continually grows with increasing technological know-how, much like the temporal variation in individual income that occurs when human capital accumulation periodically diverts time away from full-time work. Likewise, the distinction between growth and fluctuations becomes less useful since both are a manifestation of the same underlying economic phenomenon.

In the model, technological know-how is embodied in individuals and there is a nondegenerate distribution of know-how at any point in time. Individuals understand how know-how is distributed, the productivity gains that might be realized with different types 


\section{Technology Diffusion and Aggregate Dynamics}

of technological advances, and the way in which the equilibrium distribution of know-how will evolve. However, being aware of superior technology is not the same as having the know-how to implement it. To do this, individuals divert resources to a time-consuming and uncertain learning process. Following Jovanovic and MacDonald (1994) and Fricson and Pakes (1995), individuals can discover new technologies on their own, or they can also learn from one another (imitation). ${ }^{1} \quad$ The technology of learning something new via imitation is subject to an information externality. Following Schumpeter (1939), we assume that it becomes progressively easier to imitate (or refine) an idea the more extensive is its use throughout the economy. ${ }^{2}$

Many different patterns of economic development are consistent with equilibrium. In particular, depending on the parameters of the learning environment, output may either grow steadily or display cyclical variation. An uneven pattern of growth follows when developing frontier know-how is relatively difficult, and when frontier know-how represents a large improvement over older technologies. In this case, imitation is the main source of information acquisition, and new technology tends to be widely-used before it is supplanted by yet-newer methods. Once some individuals have acquired cutting-edge know-how, knowledge-laggards 1 A related search-theoretic approach has been explored by Bental and Peled (1996) and Jovanovic and Rob (1990).

2 Schumpeter (1939:100): "Considerations of this type [the difficulty of coping with new things] entail the consequence that whenever a new production function has been set up successfully and the trade beholds the new thing done and its major problems solved, it becomes easier for other people to do the same thing and even improve upon it. In fact, they are driven to copying it if they can, and some people will do so forthwith. [Hence, it follows that] innovations do not remain isolated events, and are not evenly distributed in time, but that on the contrary they tend to cluster, to come about in bunches, simply because first some, and then most, firms follow in the wake of successful innovation." Note that this interpretation of the cycle differs markedly from Schumpeter's later (1942) notion of "creative destruction", formalized by Aghion and Howitt (1992), Cheng and Dinopolous (1991), and Justman (1997). 


\section{Technology Diffusion and Aggregate Dynamics}

divert resources from production to imitation, implying a low level of current output and subsequent rapid growth, slowing as the cutting edge know-how becomes widely used. During this epoch, heterogeneity in technology in use rises as new and old techniques are simultaneously in use, then falls as the frontier know-how becomes commonplace. ${ }^{3}$ In contrast, if learning at the frontier is relatively easy, and improvements frequent, output grows smoothly and steadily.

A parameterized version of the model is employed to interpret data on the post-war U.S. economy. Since the model contains no source of "high-frequency" fluctuations, its parameters are chosen to fit "filtered" versions of the data. ${ }^{4}$ The fitting procedure delivers parameter values for preferences, production possibilities and learning technologies. An example of the kind of conclusions that emerge is as follows. In the data, aggregate income grew rapidly during both the mid-fifties and mid-sixties. After that, growth was modest until about 1980, at which point growth resumed, but at a less rapid pace. The model explains this pattern, first, as the result of a pair of large and comparatively easy-to-learn technological breakthroughs; these advances generated the two early periods of rapid growth. The second breakthrough became very widely used, and indeed, was not supplanted for about fifteen years. This gap in inventive success generated the long period of low growth. The subsequent advances led to renewed growth, but overall, they offered smaller, more incremental, improvements

3 This economy-wide diffusion of new technology is reminiscent of the rising adoption waves found in many of the Gort and Klepper (1982) products. At the aggregate level, Lippi and Reichlin (1994) estimate S-shaped diffusion patterns in U.S. real GNP data (although their diffusion rates are much higher than those estimated here). In contrast, Jovanovic and Lach (1997) find that there is too much mixing in the diffusion dynamics of individual technologies for the shape of the diffusion curve to influence the nature of the business cycle. 4 Our methodology is similar to that employed by Hornstein and Krusell (1996) and Greenwood and Yorukoglu (1997), who explain one slowdown and subsequent recovery with one change in the rate of exogenous technological progress. 


\section{Technology Diffusion and Aggregate Dynamics}

and were harder to implement. Data on the growing and fluctuating share of engineering Ph.D.s (relative to all Ph.D.s in science and engineering) support the model's technological interpretation of the growth facts, and data on patent applications and adult schooling are consistent with the notion that newer technologies are more specific and proprietary.

The structure of the paper is as follows. The next section sets out the model; this is followed by a description of the data and procedure employed to choose values for the model's parameters. Discussion then turns to interpretation of the model's parameters (many of which are new to aggregate models), the implied diffusion of new technology, the model's interpretation of the post war data, and implications about learning effort. Some evidence supporting a technology-based interpretation of the data is offered in the final section, along with discussion of the model's findings in terms of chemical- or electronics-based technologies.

\section{Model}

The objective of this paper is to explore the manner in which the discovery and spread of technological know-how can deliver equilibrium growth and fluctuations in aggregates, primarily income. The model includes only those elements needed to accomplish this task.

Time $(t)$ is discrete and the horizon is infinite: $t=0,1,2, \ldots, \infty$. Agents are fixed unit continua of identical firms and individuals. Below, technological know-how will be embodied in individuals. Thus the specification of the firm side of the economy is simple. Firms are competitive and have access to technology displaying constant returns to scale in capital services and efficiency units of labor input. Thus, without loss of generality, firms can be 


\section{Technology Diffusion and Aggregate Dynamics}

aggregated and represented by a single "large" individual-owned competitive firm whose technology displays constant returns:

$$
Q_{t}=F\left(K_{t}, H_{t}\right)
$$

where $Q_{t}, K_{t}$ and $H_{t}$ represent output, the capital stock and total efficiency units of labor services, all at date $t$.

The firm owns the capital stock, which depreciates at the proportional rate $\delta(0<\delta \leq 1)$, but can also be augmented by retaining output:

$$
K_{t+1}=(1-\delta) K_{t}+I_{t}
$$

where $I_{t}$ denotes gross investment.

Assume that the price of efficiency units of labor services is $w_{t}$, the real discount factor is $\beta(0<\beta<1)$, and that there is no aggregate uncertainty. Then the firm's problem is

$$
\max _{\left\{K_{t}, H_{t}\right\}} \sum_{t=0}^{\infty} \beta_{t}^{t} \Pi_{t}
$$

where

$$
\Pi_{t} \equiv F\left(K_{t}, H_{t}\right)-w_{t} H_{t}+(1-\delta) K_{t}-K_{t+1}
$$

Given $K_{\mathbf{0}}$, an optimal policy $\left\{K_{t}, H_{t}\right\}_{t=\mathbf{0}}^{\infty}$ for the firm will satisfy (at an interior):

$$
F_{H}\left(K_{t}, H_{t}\right)-w_{t}=0
$$

and

$$
-1+\beta\left[F_{K}\left(K_{t+1}, H_{t+1}\right)+1-\delta\right]=0
$$




\section{Technology Diffusion and Aggregate Dynamics}

Individual preferences over stochastic consumption sequences $\left\{C_{t}\right\}$ are given by

$$
E\left[\sum_{t=\mathbf{0}}^{\infty} \beta^{t} C_{t}\right]
$$

where $E$ is the expectation operator associated with the distribution of $\left\{C_{t}\right\}_{t=0}^{\infty}$. (While there is no aggregate uncertainty, individuals face idiosyncratic uncertainty as a result of randomness in the learning process set out below.) Individuals are endowed with time $T$ in each period, and may allocate it between work $\left(N_{t}\right)$ and learning activities $\left(L_{t}\right)$ :

$$
N_{t}+L_{t}=T
$$

The possibility of substituting learning for work contributes to cyclical behavior of output in the quantitative analysis. That is, when there is a lot to learn, learning will displace work, reducing current output growth. Later, the results of learning efforts both raise output and make work relatively more attractive.

An individual's technological know-how at date $t$ will be described by $x_{t}$. Assume that an individual whose know-how is $x_{t}$, and who supplies market time equal to $N_{t}$, delivers $x_{t} N_{t}$ efficiency units of labor effort in period $t .^{5}$ Then, since risk neutral individuals will not find any advantage in capital market transactions, the relevant budget constraint for a consumer with know-how $x_{i t}$ is the "period" budget constraint

$$
C_{t}=w_{t} x_{t} N_{t}+\Pi_{t}
$$

5 We assume that technological know-how is embodied in the minds of individuals. However, exactly where new technology resides is clearly an issue. At one extreme, technology may be something like a process, for which a firm has configured machines, materials, and so on in a way that allows the process to function. At the other extreme, technology may be more like chip designs, requiring specific expertise that individuals may readily carry with them as they move among employers. The paper models the latter case. 


\section{Technology Diffusion and Aggregate Dynamics}

Let $x_{t}$ belong to a finite set $X \equiv\left\{x_{1}, \ldots, x_{M}\right\}$, indexed by $i$, where $x_{i}<x_{i+1}$; normalize $x_{1} \equiv 1$ (it is assumed that the economy begins with all individuals knowing $x_{1}$ ). Since $M$ is unrestricted, as far as the quantitative analysis is concerned, this setup involves no loss of generality. Variables associated with an individual who knows $x_{i}$ at $t$ will be subscripted by $i t$.

How does $x_{t}$ evolve? Individuals can improve their know-how in two ways, similar to the innovation and imitation possibilities through which firms learn in Andolfatto and MacDonald (1991) and Jovanovic and MacDonald (1994). If an individual whose know-how at $t$ is $x_{i}$ chooses to innovate and devotes time $L$ to this activity, $x_{i+1}$ is learned with probability $\gamma_{i+1} \varphi(L)$, and nothing is learned (in particular, $x_{i+2}, x_{i+3}, \ldots$ ) otherwise; $\gamma_{i+1}$ is a fixed parameter describing the difficulty of discovering in isolation how to improve over $x_{i}$, and $\varphi$ is an increasing and concave function with $\varphi(0)=0$ and $\varphi(T) \leq 1 / \max _{i}\left\{x_{i}\right\}$. $^{6}$ Should the individual, again knowing $x_{i}$, choose to imitate instead, $x_{i+1}$ is learned with probability $\lambda_{i+1} \varphi(L)$, and nothing is learned otherwise; here $\lambda_{i+1}$ is the fraction of individuals knowing $x_{i+1}$ but no more advanced technology. Note that the substantive distinction between innovation and imitation is that success in the former activity depends primarily on what the individual currently knows and on the nature of the new technology to be implemented, while success in the latter activity depends primarily on the extent to which what is to be learned is currently in use throughout the economy. Assuming that at most one of inno6 Observe that $\varphi$ does not depend on $i-$ i.e. the difficulty of imitation is independent of the size of the innovation. This restriction is a significant one in that if a technology diffuses comparatively slowly, the model always attributes this to the technology not being valuable (large) enough to be worth learning quickly, as opposed to its being comparatively difficult to learn from others. This produces an artificial link between how quickly a technology diffuses and its magnitude. 


\section{Technology Diffusion and Aggregate Dynamics}

vation and imitation can be selected in any period, the individual will always select the learning mode yielding the highest success probability. Thus the probability with which the individual learns $x_{i+1}$ given know-how of $x_{i}$ is

$$
\xi_{i}\left(L_{i t}\right)=\max \left\{\gamma_{i+1}, \lambda_{i+1}\right\} \varphi\left(L_{i t}\right)
$$

Let $\Gamma \equiv\left(\gamma_{2}, \ldots, \gamma_{M}\right)$ and $\Lambda_{t} \equiv\left(\lambda_{1 t}, \ldots, \lambda_{M t}\right) ; \Lambda_{0}$ is exogenous.

This setup has two special features that simplify, but are otherwise "unattractive." One is that given the continuum of individuals and (3), some individuals may come to know $x_{M}$ in the $M^{\text {th }}$ period of the economy; this feature appears in the quantitative analysis. However, because observed output growth is both positive on average and fluctuating, the model's parameters must be chosen so that successful innovation is relatively infrequent, and imitation is the main source of the model's dynamics. The few individuals who learn advanced technologies early, therefore, have negligible effect on the quantitative analysis because the many individuals whose know-how is far less advanced cannot imitate them. Second, if an individual is left behind - in the sense of knowing $x_{i}$ when most others have learned at least $x_{i+2}$ - successful imitation is very unlikely. This is a reasonable assumption in that, arguably, many new technologies are hard to learn without some knowledge of the workings of their recent predecessors. In the quantitative analysis, this feature of the model is unimportant in that, to fit the data, the parameters are such that by the time a new technology starts to become widely known, most individuals have already learned its predecessor.

The problem faced by an individual whose know-how at $t$ is $x_{i}(i<M)$, may be repre- 


\section{Technology Diffusion and Aggregate Dynamics}

sented by

$$
V_{i t}=\max _{L_{i t}}\left\{w_{t} x_{i}\left(T-L_{i t}\right)+\Pi_{t}+\beta\left[\xi_{i}\left(L_{i t}\right) V_{i+1, t+1}+\left[1-\xi_{i}\left(L_{i t}\right)\right] V_{i, t+1}\right]\right\}
$$

Assuming that $\xi_{i}$ can be differentiated, an optimal choice of $L_{i t}$ satisfies (at an interior): ${ }^{7}$

$$
-w_{t} x_{i}+\beta \xi_{i}^{\prime}\left(L_{i t}\right)\left(V_{i+1, t+1}-V_{i, t+1}\right)=0
$$

where for $i=M, L_{t}=0$.

Equations (1),(2),(4) and (5) describe individual behavior. The remaining equilibrium conditions specify that the labor market clear:

$$
H_{t}=\sum_{i=1}^{i=M} \lambda_{i t} x_{i}\left(T-L_{i t}\right),
$$

and that the evolution of $\Lambda_{t}$ be consistent with the learning technology and the aggregation of individual learning efforts:

$$
\lambda_{i, t+1}= \begin{cases}{\left[1-\xi_{i}\left(L_{i t}\right)\right] \lambda_{i t}} & i=1 \\ & \\ {\left[1-\xi_{i}\left(L_{i t}\right)\right] \lambda_{i t}+\xi_{i-1}\left(L_{i-1, t}\right) \lambda_{i-1, t}} & i>1 .\end{cases}
$$

Altogether, an equilibrium is a vector $\left(\left\{K_{t}, H_{t}, \Pi_{t}\right\}_{t=\mathbf{0}}^{\infty},\left\{w_{t}\right\}_{t=\mathbf{0}}^{\infty},\left\{\Lambda_{t}\right\}_{t=\mathbf{0}}^{\infty},\left\{L_{i t}, V_{i t}\right\}_{i=1, t=\mathbf{0}}^{i=M, t=\infty}\right)$ such that $(1),(2),(4),(5),(6)$ and $(7)$ are satisfied for all $i$ and $t$.

\section{Data and Parameterization}

The theory delivers time paths for a number of commonly-examined economic aggregates: output, consumption, labor input, capital input and wages. The corresponding data (details 7 For the parameter values considered below, the solutions are interior. 


\section{Technology Diffusion and Aggregate Dynamics}

described in the Appendix) are annual series, for 1946-1994, on real per capita GNP, real per capita consumption expenditures (private and public), per capita hours of work, real per capita wages, and real per capita net stock of fixed nonresidential structures and equipment (private and public).

In order to compare the model and data, what "version" of the data should be employed? In the standard real-business-cycle analysis, growth is ignored and the conventional datamodel comparison is based on data whose (nonlinear) trend has been removed by taking deviations from HP-filtered series; see, for example, Cooley and Prescott (1996). Here, with both growth and fluctuations being important, this particular treatment of the data is not helpful. The model delivers fluctuations at the frequency with which major innovations diffuse. Thus, realistically, it cannot yield high frequency fluctuations, and making comparisons to the raw data is less informative than comparisons to series with less high-frequency variation. The method adopted here is to focus on HP-filtered series (not deviations from filtered series). Specifically all series are smoothed using an IP filter with smoothing parameter equal to 10 . For the purpose of choosing parameters, it turns out that the choice of the smoothing parameter is virtually irrelevant provided the parameter is less than 100 for annual data. In particular, fitting the model to the raw data (i.e., HP smoothing parameter equal to zero) does not substantially alter the parameter estimates reported below, and hence would generate an equilibrium time path for output that closely resembles the HP-filter with smoothing parameter equal to 10 . The value of 10 for the smoothing parameter was chosen primarily because the relevant features of the data are particularly easily 


\section{Technology Diffusion and Aggregate Dynamics}

displayed graphically. ${ }^{8}$ For example, Figure 1 displays the raw and filtered (dashed series) GNP data.

Functional forms are required for the production technology $F$ and the learning technology $\xi$. The choice of $F$ is standard:

$$
F(K, H)=A K^{\alpha} H^{1-\alpha}
$$

where $\alpha$ is a parameter; $0<\alpha<1$, and $A>0$. This specification of the aggregate technology is chosen because, in conjunction with the embodiment of technology in human capital, it readily produces both wage growth and no trend in returns to capital, as per the data. ${ }^{9}$

Less guidance is available for the choice of $\xi$. The specification chosen here is

$$
\varphi(L)=1-e^{-\theta L / T}
$$

where $\theta$ is a parameter; $\theta>0$.

There are various ways to proceed quantitatively. On one extreme, basic features of the data, augmented with other evidence, might be used to select values for the parameters. For example, $\alpha$ could be set equal to capital's average share of income; this is the familiar

8 The filtered series with smoothing parameters $3,5,10$ and 100 are difficult to distinguish from one another in a time series plot, whereas the raw data fluctuate significantly more. Evidently, for smoothing parameters in this range, the main features of the smoothed series are not greatly affected. For example, consider the means and standard deviations of GNP growth for the raw data and smoothed series:

\begin{tabular}{|l|l|l|}
\hline & Mean & S. D. \\
\hline Raw & .0172 & .0310 \\
\hline HP3 & .0172 & .0135 \\
\hline HP5 & .0174 & .0125 \\
\hline HP10 & .0175 & .0114 \\
\hline HP100 & .0180 & .0095 \\
\hline
\end{tabular}

9 There is, however, some evidence suggesting that it is not descriptive as a plant-level specification; i.e., see Bahk and Gort (1993). 


\section{Technology Diffusion and Aggregate Dynamics}

"calibration" approach. At the other extreme, the parameters can be chosen to fit the data in the sense of maximizing some measure of goodness of fit - "estimation". The route followed here is of the latter variety. The reasoning is simply that the parameters fall into two groups - those for which there is information sufficient to allow a reasonable choice of

the parameter, and all others. For this model the second group is large, implying that some degree of estimation is required. While calibrating the first group is possible ( $\alpha$ and $\beta$, for example), it turns out that the estimated values for these parameters differ little from what a calibration would deliver.

The parameters are chosen to minimize the discrepancy between the five series described above and the corresponding equilibrium time series implied by the model, given parameter values. There are many metrics that might be employed to gauge the magnitude of this discrepancy. Let $y_{k}$ be the vector of data on the $k^{\text {th }}$ variable, and $\widehat{y}_{k}$ be the corresponding series from the model. The metric employed here is

$$
-\sum_{k}\left(\ln y_{k}-\ln \widehat{y}_{k}\right)^{\prime}\left(\ln y_{k}-\ln \widehat{y}_{k}\right)
$$

One motivation for this metric is the fact that it is proportional to the concentrated loglikelihood function that would follow by assuming $\ln y_{k t}$ differs from $\ln \widehat{y}_{k t}$ by a normal random variable $\varepsilon_{k t}$, where $\varepsilon_{k t}$ is independent of both $\varepsilon_{k t^{\prime}}$ and $\varepsilon_{k^{\prime}} t$.

To keep the number of parameters to be estimated manageable, the number of knowledge states $(M)$ and the initial distribution of know-how $\left(\Lambda_{0}\right)$ are not estimated. Some experimentation revealed that there was little to be gained by allowing $M>7 ; M=7$ is imposed. Likewise, experimentation reveals that the correspondence between model and data is con- 


\section{Technology Diffusion and Aggregate Dynamics}

sistent with a relatively concentrated initial distribution. Thus $\Lambda_{0}=(.98, .02,0,0,0,0,0)$ is assumed. With these assumptions, nineteen parameters remain to be estimated: $K_{\mathbf{0}}$ and $\delta$, $\beta, T, \alpha, A, x_{2}, \ldots, x_{7}, \gamma_{2}, \ldots, \gamma_{7}$ and $\theta$. These parameters will be estimated numerically by minimizing $(8) \cdot{ }^{10}$

\section{Results}

The parameter values and their interpretation are discussed first. Then, attention is directed to the innovation and diffusion behavior implied by the model. There is no data to compare to these predicted paths, but focusing some attention on them greatly facilitates the discussion of the explanation the model offers for the patterns in the data, which follows last.

\subsection{Parameter Values}

Estimated parameter values appear in the table following.

10The minimization follows the standard methodology: Given a parameter vector, the model's equilibrium is computed numerically. The equilibrium is then used to calculate the series to be compared to the data, and (8) is then obtained from the data and the computed series. 
Technology Diffusion and Aggregate Dynamics

\begin{tabular}{|l|l|}
\hline \multicolumn{2}{|c|}{ Estimated Parameter Values } \\
\hline$K_{\mathbf{0}}, \delta$ & $4688,0.1263$ \\
\hline$\beta$ & 0.8349 \\
\hline$T$ & 1156.91 \\
\hline$\alpha, A$ & $0.4804,0.9056$ \\
\hline$x_{2}, \ldots, x_{7}$ & $1.3169,1.4949,1.8548,2.1814,2.2658,2.2665$ \\
\hline$\gamma_{2}, \ldots, \gamma_{7}$ & $0.1267,0.1366,0.2355,0.0364,0.2022,0.1991$ \\
\hline$\theta$ & 10.0144 \\
\hline
\end{tabular}

The parameters $K_{\mathbf{0}}, \delta, \beta, T, \alpha$ and $A$ appear in most dynamic general equilibrium models, and are of lesser interest. However, if unrealistic values are needed for the model to fit the data, this would be an indication that the model is a poor abstraction. Thus, consider these parameters first, as a "specification check".

\subsection{1 $K_{0}$}

The estimate of the initial capital stock, $\$ 4688$, is $11 \%$ below the actual figure for 1946 . The source of this discrepancy is clear. The capital stock declined in the late 1940's, and did not exceed its 1946 value until 1950. Given the labor-augmenting form of technical progress and the capital-labor complementarity implicit in the production technology, it is difficult for the model to deliver a capital stock series that declines at any point. Thus, if the model were to fit the 1946 value of the capital stock more closely, it would produce a capital series that is above the actual for a significant period, and thus match the capital stock series poorly overall. 


\section{Technology Diffusion and Aggregate Dynamics}

\subsection{2 $\delta$}

The annual physical depreciation rate of capital is estimated to be $12.63 \%$. This value is within the range of values commonly used; see Prescott (1986).

\subsection{3 $\beta$}

The estimated discount factor, 0.8349, is somewhat lower than the values typically encountered. With a higher value for the discount factor the model delivers a consumption path that is below that observed in the data. This may be a consequence of assuming risk neutral consumers - that is, consumers who do not value consumption smoothing. Since technology is always improving, investment in capital is attractive. And with a high discount factor,

consumers find the cost of delaying consumption small. Thus, while the estimated value is lower than commonly assumed, it is not wildly implausible, and may be traced to one particular, but not essential, part of the model's specification.

\subsubsection{T}

The parameter $T$ is interpreted as the annual amount of time that the representative consumer divides between work and information acquisition activities. The quantitative analysis assumes that observed hours of work are entirely time spent working, and not time devoted to learning. Under this assumption, the estimated value of $T, 1156.91$, implies that (since observed average annual hours are 1087) on the average, about $94 \%$ of the time endowment is devoted to work; the maximum in the data is $99.6 \%$ and the minimum $87.6 \%$. Observe that this implies very large proportional variation in the time devoted to learning activities. 


\section{Technology Diffusion and Aggregate Dynamics}

\subsection{5 $\alpha$ and $A$}

In the data, the average value of capital's share of income is .40 , whereas the estimated value of $\alpha$ is .48. That these values differ to some degree is not surprising in that the estimation procedure makes no direct use of the fact that $\alpha$ is capital's share; instead, it fits the components of the share series-by-series. $A$ is simply a scaling parameter.

\subsection{6 $x_{2}, \ldots, x_{7}$}

The parameters $x_{2}, \ldots, x_{7}$ represent the successive technology parameters, measured relative to the technology widely used as of 1946 - i.e. $x_{1} \equiv 1$. They are most revealingly interpreted as successive proportional improvements - i.e. $\left(x_{2}-x_{1}\right) / x_{1},\left(x_{3}-x_{2}\right) / x_{2}$, etc. The six estimated values are then $0.3169,0.1352,0.2408,0.1761,0.0387$ and 0.0003 . Thus, according to the model, the first major innovation to diffuse after the second world war was very large - roughly twice as large as any that followed, and four times the median. While six values are too few to make strong statements about the distribution of possible technological improvements, these values are most consistent with it being quite positively skewed- i.e. many moderate improvements and a few very large ones. ${ }^{11}$ Below, the size and order of these improvements will be employed to interpret the post-war data.

11Even if the first large innovation is more appropriately explained as a reaction to resources no longer being directed towards the war effort, the distribution of the other improvements is still quite positively skewed. While interpreting the first innovation this way may seem reasonable, it will become clear from what follows that there is no correspondingly large innovation following the Korean war (mid-1950 through 1954). 


\section{Technology Diffusion and Aggregate Dynamics}

\subsection{7 $\gamma_{2}, \ldots, \gamma_{7}$}

The parameters $\gamma_{2}, \ldots, \gamma_{7}$ describe innovation difficulty. Their levels primarily dictate how long it will be before imitation becomes a more attractive way to learn, in comparison to innovation. When $\gamma$ is low, for an innovation of a given magnitude, use of the corresponding innovation will begin slowly, since innovation is hard, but diffuse rapidly as contagion-style learning supplants innovation. The values $0.13,0.14,0.24,0.04,0.20,0.20$ display negative skewness - the hardest-to-innovate technology is about three times as difficult to innovate as the next most difficult.

The difficulty of learning seems to be (loosely) inversely related to the importance of what is to be learned. For example, the least important innovations $(i=6$ and $i=7)$ are among the easiest to learn via innovation, and the largest $(i=2)$ innovation is harder to learn than average. On the other hand, the hardest-to-learn technology $(i=5)$ is less important than average. Altogether, the correlation between $\gamma_{i}$ and $\frac{x_{i+1}-x_{i}}{x_{i}}$ is negative $(-0.27)$. If the $\gamma_{i}$ and $\frac{x_{i+1}-x_{i}}{x_{i}}$ are viewed as describing the nature of the some creative process, there is no reason to expect them to be related. However, to the extent that individuals select which technology to try to learn, the only minor innovations that would attract resources are those that are easy to learn; presumably all available major innovations would be explored. In this case a loose negative relation between $\gamma_{i}$ and $\frac{x_{i+1}-x_{i}}{x_{i}}$ would emerge. The calculations offer some support for this idea: the three largest innovations range from the most difficult to easiest to learn, but the three smallest innovations are all relatively easy to learn. 


\section{Technology Diffusion and Aggregate Dynamics}

\subsection{8 $\theta$}

The value of $\theta$ is difficult to interpret directly; however, it implies, for the sample average number of hours of work, a learning technology equal to $\max \left\{\gamma_{i+1}, \lambda_{i+1}\right\} \times .447$, and an elasticity of $\varphi$ with respect to $L$ of .74 .

\subsection{Diffusion of New Technology}

Figure 2 displays the equilibrium diffusion paths given the estimated parameters - i.e., for each date, the proportion of individuals knowing technology $i$. While there is no data for comparison, the diffusion paths influence the shape of the model's predicted series and are the explanation the model offers for the behavior of the data. The Figure also contains summary information that will be helpful later - for example, technology two is a "large" improvement over the existing know-how, and about "average" in terms of innovation difficulty. ${ }^{12}$

Technologies two through six diffused during the period covered by the data; the extent of use of technology seven was still increasing in 1994. Technology two diffused quickly precisely because it was not hard to discover, and its large size meant putting it to use was quite valuable. Evidently, it was simultaneously employed by over $70 \%$ of individuals at its peak usage. In contrast, technology three was only trivially harder to innovate, but offered only a small improvement. At the peak it was employed by less than $40 \%$ of individuals, despite the (assumed) fact that technology three had to be learned in order to have any chance of using technology four, which offered a bigger improvement. Put another way,

12The coexistence of technologies is also a feature of many vintage-capital models; see, for example, Chari and Hopenhayn (1991). 


\section{Technology Diffusion and Aggregate Dynamics}

technology three would not attract a lot of learning effort if all that was to be gleaned was access to technology three. Those who already new how to use technology two stood to gain little by obtaining technology three other than access to technology four, which offered a substantial improvement. Since technology four was relatively easy to learn with technology three in hand, and also diffused quickly - opening up good prospects for imitation - use of technology three came and went relatively quickly for any individual. Thus, although essentially all individuals employed technology three at some point, comparatively few used it at any particular point in time, and it never became a "dominant" technology. In contrast, technology four achieved broad acceptance - nearly $90 \%$ of individuals where simultaneously using it at its peak acceptance. The reasons for this are two-fold. First, as mentioned, exit from technology three was relatively quick. And second, exit from technology four was comparatively slow. The reason for this is that technology five offered a smaller improvement than technology four, was relatively hard to innovate, and, evidently, only opened the door to modest technological improvements. Once technology five was in common-enough use for diffusion by imitation to be practical, its size was sufficient to cause it to become fairly widely employed - in simultaneous use by over $60 \%$ of individuals at the peak. However, even though the next pair of new technologies were minor advances, they were sufficiently easy to learn that they caused exit from technology five before it became as dominant as either of the other large innovations.

One other diffusion-related issue deserves mention. Figure 3 displays the diffusion paths in the top panel and the standard deviation of know-how over time - i.e. the standard 


\section{Technology Diffusion and Aggregate Dynamics}

deviation of the estimated $\Lambda_{t}$ - in the bottom. Overall, this dispersion of technological knowhow shows a negative trend. One source of this trend is that the earlier innovations offered greater improvements, in which case simply having more than one technology in use implied wide dispersion; the early fifties, when only technologies one and two were widely used, is an example. Of course, even if improvements are not large, they may be easy to acquire, so that there are relatively many technologies in use simultaneously. This also generates dispersion in know-how; the early and middle eighties are an example of this phenomenon. However, in the data, the technologies in use later in the sample period are too similar to generate the kind of dispersion witnessed earlier. Overall, these results are consistent with the notion that innovations are becoming more "incremental" in the sense of their being smaller and more related to one another.

Another way to look a this phenomenon is displayed in Figure 4. The series depicted is

$$
\sum_{i=1}^{i=6} \lambda_{i t} \frac{\left(x_{i+1}-x_{i}\right)}{x_{i}}
$$

which can be interpreted as a measure of the date $t$ opportunities for technological improvement. At the outset, the technology in use is almost exclusively technology one, and technology two provides an improvement of over $30 \%$; thus the series takes on a value of just over .3. This series has an annual growth rate of $-4.2 \%$, declining by nearly an order of magnitude over the sample period. 


\section{Technology Diffusion and Aggregate Dynamics}

\subsection{Actual and Predicted Evolution of Aggregates}

\subsubsection{Income}

The model studied here can in some sense be regarded as a theory of the HP-filter. ${ }^{13}$ From

Figure 5, it is not hard to see why. In Figure 5 the dashed series is the series predicted by the model. The diffusion of new technologies delivers a time series of income that grows and fluctuates in a manner with obvious similarities to the data. Again, herein, growth and fluctuations are simply different aspects of the same general phenomenon - new technology provides opportunities for growth in income, and the resource-consuming activities required for these opportunities to come to fruition imply fluctuations.

The model's parameters were chosen to fit the data in levels - including both trend and fluctuations. Nevertheless, as Figure 6 illustrates, the level and variability of growth rates in the data and predicted series have much in common. In the data, the average annual growth rate is $1.75 \%$, with standard deviation $1.14 \%$; the corresponding figures for the model are $1.77 \%$ and $1.33 \%$. While the model reproduces the gross features of GNP growth, the model predicts growth that picks up more slowly than is observed in the data, at least early in the sample. This feature of the analysis will come up again in connection with the behavior of consumption. $^{14}$

The underpinnings of the general patterns in the growth rates are evident from the diffusion paths set out above, reproduced below along with the predicted growth rate. The

13We thank Jeff Campbell for bringing this to our attention.

14 One possible explanation for this is that the initial distribution of know-how has been assumed to be too concentrated. This error would delay imitation and rapid diffusion. Experimentation with the assumed initial distribution shows that this is not the explanation. A more plausible explanation is that the imitation technology $-\lambda_{i+1} \varphi\left(L_{i t}\right)$ - is overly restricted, and that some concavity in $\lambda_{i+1}$ is called for. Concavity would deliver more rapid diffusion at lower levels of use of the new technology. 


\section{Technology Diffusion and Aggregate Dynamics}

first two periods of rapid growth follow from the diffusion of the two large technological improvements - technologies two and four. The long period of modest growth follows from technology four being widely used while technology five was still in its (difficult) innovation phase. The diffusion of technology five delivers the final period of higher growth. The connection between technological heterogeneity and growth is apparent from Figure 8. Note that dispersion tends to lead growth. This is a consequence of imitation playing such a key role. Rising dispersion is an indication of improving imitation opportunities, leading to growth through wide-spread use of better techniques. Also note that, in the model, the distribution of wage income is closely tied to the dispersion in technological know-how. Consequently, the model predicts that high levels of income inequality are associated with periods of rising growth. ${ }^{15}$

\subsubsection{Other Aggregates}

The model also has implications for the other four series of interest - consumption, wages, the capital stock and hours. The data and the model's predicted paths are displayed in Figures 9-12. With the exception of the hours data, the series predicted by the model have features similar to the data. The source of the discrepancy in hours is clear. The assumption that a fixed time endowment is divided between work and learning effort implies that periods where there is a lot of learning must be associated with low hours of work. Thus, during the diffusion of the two large innovations early in the sample period, the model must predict low hours, whereas the data are the opposite. Likewise, during the long period where technology

15The dispersion in discounted lifetime income is about half (in percentage terms) that of income and displays considerably less cyclical variability. 


\section{Technology Diffusion and Aggregate Dynamics}

four was dominant, the model must predict high hours, whereas the data display low hours. Part of this discrepancy is a consequence of assumption that observed hours of work do not involve time spent learning. In all likelihood, this is counterfactual. Further, the analysis ignores the work/learning versus leisure margin, inclusion of which would raise hours early and lower them during the period of technology four's dominance.

\subsubsection{Summary of Actual and Predicted Evolution of Aggregates}

The table following contains the means and standard deviations for the actual and predicted values of the series of interest; the correlation between the data and the model's predictions is included as well.

\begin{tabular}{|c|c|c|c|c|c|c|c|c|c|c|}
\hline & \multicolumn{5}{|c|}{ Levels } & \multicolumn{5}{|c|}{ Growth Rates (\%) } \\
\hline & \multicolumn{2}{|c|}{ Data } & \multicolumn{2}{|c|}{ Model } & \multirow[t]{2}{*}{ Corr. } & \multicolumn{2}{|c|}{ Data } & \multicolumn{2}{|c|}{ Model } & Corr. \\
\hline & Mean & S. D. & Mean & S.D. & & Mean & S.D. & Mean & S.D. & \\
\hline Consumption & 4490 & 1151 & 4479 & 1095 & 0.9954 & 2.06 & 1.27 & 2.01 & 2.25 & 0.47 \\
\hline Income & 5660 & 1302 & 5666 & 1308 & 0.9981 & 1.75 & 1.14 & 1.77 & 1.33 & 0.79 \\
\hline Hours & 1084 & 26.73 & 1088 & 17.87 & -0.3617 & -0.02 & 0.51 & 0.00 & 0.46 & 0.11 \\
\hline Wages & 3.092 & 0.576 & 3.124 & 0.699 & 0.9819 & 1.24 & 1132 & 1.72 & 1.09 & 0.68 \\
\hline Capital & 8416 & 2169 & 8329 & 1955 & 0.9665 & 1.58 & 1.71 & 1.84 & 1.49 & 0.42 \\
\hline
\end{tabular}

\subsection{Measures of Learning}

The theory interprets the data on growth and fluctuations in terms of development and spread of new technological know-how. Features of the manner in which new know-how influences the economy - the magnitude of productivity increases, how difficult is it for the ideas to spread, etc. - are inferred from the data on the assumption that this interpretation of the data is correct.

The model also makes predictions about efforts to learn. Figure 13 presents the diffusion paths discussed earlier, along with the model's predicted time series of labor effort devoted 


\section{Technology Diffusion and Aggregate Dynamics}

to learning as a fraction of total output (bottom panel). Two points are noteworthy. First, the value of resources devoted to learning make up a small fraction of (about 3\%) of income. Second, learning effort peaks early in the period during which new technology diffuses, and before the time of most rapid diffusion. This highlights the role of imitation. That is, as new technology diffuses, imitation becomes easier, allowing more rapid diffusion with fewer aggregate resources. The countercyclical nature of learning efforts is apparent from Figure 14. For comparison purposes, Figure 15 displays HP-filtered aggregate R\&D expenditures as a proportion of GNP alongside the predicted resources devoted to learning (1954 is the earliest year for which a consistent R\&D series is available. $)^{16} \quad$ The predicted learning effort series leads the R\&D series, and they share the pair of upswings associated with the two (just two, as a result of the shorter period over which data are available) diffusions of new technology.

Some more direct measurements of attempts to learn and development of new ideas are presented in the figures following. Patents are one way to measure the extent to which new technological know-how is evolving. Figure 16 displays the growth rate of smoothed (again, using the HP filter with smoothing parameter equal to ten) patent applications for inventions, per capita, along with the estimated diffusion of new technology discussed earlier.

It is apparent that an increase in patent applications occurred during the beginning of the periods in which the two, major technological advances diffused. The later, and smaller, technological improvement coincides with a more substantial increase in the application rate;

16The data discussed in this section are from: U.S. Bureau of the Census, Historical Statistics of the United States, Colonial Times to 1970, Bicentennial Edition, Parts 1 and 2; and Washington, D.C., 1975. U.S. Bureau of the Census, Statistical Abstract of the United States, Various issues, Washington, D.C. 


\section{Technology Diffusion and Aggregate Dynamics}

this is discussed further in the concluding section. These data support the model's assumed connection between growth and technological advance. Observe also that the periods of maximal patent application lag the periods during which the model predicts maximum learning efforts.

The next figure repeats the information on diffusion, but compares it to growth in school enrollment of adults (eighteen years or older, enrolled in any educational institutions, per capita, and smoothed). School enrollment can be interpreted as general human capital investment accompanying innovation and diffusion of new technology. A clear connection between diffusion of the two major technological advances and human capital investment is apparent; the association with the later advance is less clear. This, too, will be discussed in the concluding section.

\section{$5 \quad$ Summary and Conclusions}

The paper develops and analyzes a model in which aggregate dynamics are the result of individuals' efforts and success at putting new technologies to work. It takes the creative/inventive process as given, but endogenizes the link between inventions and the eventual adoption of technologies based on them. As such it takes a step in the direction of explaining temporal variation in technology.

The model interprets the key facts of post war growth - three periods of significant growth, declining in size, with the second and third separated by a long period of low growth - as the outcome of diffusion of technologies that differ both in the degree to which 


\section{Technology Diffusion and Aggregate Dynamics}

they improve over what exists already, and the difficulty of basing innovations on them.

Newer inventions appear to offer increasingly modest improvements, implying decreasing heterogeneity in technological know-how.

The model can be modified or improved in several ways:

1. It is assumed that technological know-how is embodied in people, and stresses heterogeneity across agents. A different approach assumes that knowledge resides in firms, and emphasizes inter-firm heterogeneity; this is the route explored by Andolfatto and MacDonald (1991). While the magnitude of the estimated technological improvements is reasonably insensitive to which of these approaches is followed, the conclusions about learning difficulty are not. Indeed, the second approach implies that the early, large, breakthroughs were very hard to implement, and that there was a significant buildup of firms using older technology prior to each major expansion. Determining which approach yields a better explanation of the facts would be a useful extension.

2. The poor performance of aggregate models in explaining the evolution of hours is well known; see, for example, Kydland (1996). However, the model studied herein may be capable of delivering a much improved treatment of hours. In particular, treating observed hours as the sum of work and learning time, and allowing a work/learning versus leisure margin, might improve the models performance markedly.

3. The model allows innovation difficulty to vary with each new technology, but restricts the imitation possibilities not to vary in this dimension. This is one source of the model's difficulty in delivering predicted growth that accelerates as quickly as does early post- 


\section{Technology Diffusion and Aggregate Dynamics}

war growth. Dropping this restriction might also improve the model's performance.

4. Some of the counterfactual volatility of growth is due simply to the assumption that individuals are risk neutral. While this simplifies, its impact on the model's ability to fit the facts may be significant and should be explored further.

It is perilous, not to mention somewhat outside of the macroeconomic tradition, to attempt to identify any particular technological event with a change in the aggregate technology. However, as more such changes are endogenized, and more of their structure uncovered, some attempt to find corresponding new technologies is called for. The technologies that the theory points to are the "general purpose technologies" - see the discussion and references in Bresnahan and Trajtenberg (1995) - whose introduction influences entire classes of more specific production processes. Evidently, based on Jovanovic and Lach's work, the type of technologies measured by Gort and Klepper are narrower in scope than those whose aggregate influence is deduced here; this is consistent with the observation that the Gort-Klepper data are organized in terms of products (e.g. automobile tires) rather than technologies used to manufacture them.

A natural interpretation of the first post-war improvement $\left(x_{2}\right)$ is that it represents the class of innovations associated with the "chemicals revolution" of the 1950s. The knowledge of molecular structure acquired in the years during and subsequent to the war made it possible to create a wide array of synthetic materials (e.g., plastics, synthetic fibres, packaging materials, synthetic rubber, lightweight thermal insulation, water-repellant coating, high-strength adhesives, etc.), which allowed a wide-spread shift from a reliance on organic 


\section{Technology Diffusion and Aggregate Dynamics}

materials to inorganic sources. In addition, the early post-war period witnessed tremendous productivity gains in agriculture as a result of the increased utilization of chemical inputs such as synthetic nitrogen fertilizers, herbicides and pesticides. As documented by Brady (1961) and Rosenberg (1972), the growing usefulness of the knowledge of chemical processes to the transformation of materials during this time greatly expanded the industrial area over which such knowledge became relevant. The scope of this expansion may be appreciated by recognizing that chemicals industries include practically all metallurgical refining; all refinement of fuels such as petroleum, natural gases and coal; the processes of refining materials leading to the production of cement, rubber, glass, etc.; and, indeed, any industry involved in either breaking down the molecular structure of materials or in reassembling them to make new compounds or materials.

The subsequent two technological improvements $\left(x_{3}, x_{4}\right)$ might be interpreted as representing the "electronics revolution" of the 1960s. The revolution in electronics was made possible by some earlier advances in quantum mechanics that led to an understanding of the determinants of electrical conductivity in terms of the atomic structure of crystalline solids. Solid state physics made semiconductor devices such as diodes and transistor possible; these developments in turn became indispensable inputs for a number of technological developments, such as computers, nuclear reactors, improved communication networks, and lasers (Rosenberg, 1972). As well, such devices facilitated the use of numerical control and robotics in manufacturing, which have been described by some as one of the century's most important innovations (Mansfield, et. al., 1977). ${ }^{17}$ 


\section{Technology Diffusion and Aggregate Dynamics}

While electronics (i.e., microprocessors) have become much more wide-spread in the last decade, the model suggests that its earlier incursion - transistors, solid state electronics,... - had a greater impact on aggregates, and that if anything, the magnitude of technical advances has diminished over time. There are many reasons why this might be the case. One is that the legal vehicles for protecting proprietary information may have become less effective, speeding the diffusion of what is discovered, but reducing the incentive to invent in the first place. Another possibility is that the earlier developments were the consequence of technical advances during the second world war and the space program, many of which had both numerous possible applications and few attempts to make them proprietary; the later developments may have been more narrow, or more protected by their inventors. The rapidly-rising personal and corporate marginal tax rates of the sixties may also have been an important deterrent to investment in new ideas.

All of these possibilities are consistent with the data employed to estimate the model. However, patent data point towards an explanation emphasizing a more proprietary nature of the newer breakthroughs. That is, Figure 18 plots the data on growth of patent applications alongside income growth. ${ }^{18}$ After the mid 1970s, the diffusion of the third sizeable technological breakthrough, and the associated income growth, are both accompanied by rapid growth of patent applications.

Figure 19 plots GNP growth and data on the proportion of adults in enrolled in school.

According to Lynn (1966:89), "Numerical control is probably the most significant new develoopment in manufacturing since Henry Ford introduced the concept of the moving assembly line."

18The data discussed in this section are from: U.S. Bureau of the Census, Historical Statistics of the United States, Colonial Times to 1970, Bicentennial Edition, Parts 1 and 2; and Washington, D.C., 1975. U.S. Bureau of the Census, Statistical Abstract of the United States, Various issues, Washington, D.C. 


\section{Technology Diffusion and Aggregate Dynamics}

This figure suggests that newer technological advances are more specific in nature, and rely less on the accumulation of general human capital. Indeed, after the mid 1970s, growth of adult schooling and GNP growth are negatively correlated, consistent with the notion that newer advances are more narrow, or less "general purpose." In this case new know-how is more likely to require a substitution away from the accumulation of general skills and towards technology-specific human capital. This is also consistent with the comparatively rapid growth of the more narrowly-focused programs provided by two-year colleges - in 1970, $27 \%$ of students enrolled in two-and four-year colleges, universities and professional schools were enrolled in two-year colleges; the comparable figure for 1990 is $37.9 \%$.

A final piece of evidence suggesting a technological underpinning - a human capital-based one, in particular - for growth and fluctuations comes from the data on advanced degrees in science and engineering. ${ }^{19}$ The raw data are the number of Doctoral degrees awarded in the four areas that define "hard" science in the data: (1) Physics, astronomy, chemistry and earth sciences; (2) Mathematics and Computer Science; (3) Engineering; and (4) Basic medicine and other biological sciences. All of these areas experienced dramatic post war growth. Thus Figure 20 depicts the four series expressed as a proportion of the total; the series are HP-filtered. The physical sciences show a steady downward trend, with their decline being met by a modest increase in mathematics and computer science, and biological science, and a more rapid emergence of engineering. The fluctuations are primarily an engineering/biological science substitution. The relevance of this phenomenon is suggested

${ }_{19}$ Again, see U.S. Bureau of the Census, Historical Statistics of the United States, Colonial Times to 1970 , Bicentennial Edition, Parts 1 and 2; and Washington, D.C., 1975. U.S. Bureau of the Census, Statistical Abstract of the United States, Various issues, Washington, D.C. 
Technology Diffusion and Aggregate Dynamics

by Figure 21, which plots growth in engineering's share and GNP growth. Evidently, there is some sort of connection between what engineers do or know, and income growth. 
Technology Diffusion and Aggregate Dynamics

\section{FIGURE 1}

U.S. Real per Capita GNP and HP Trend

$($ Smoothing Parameter $=10$ )

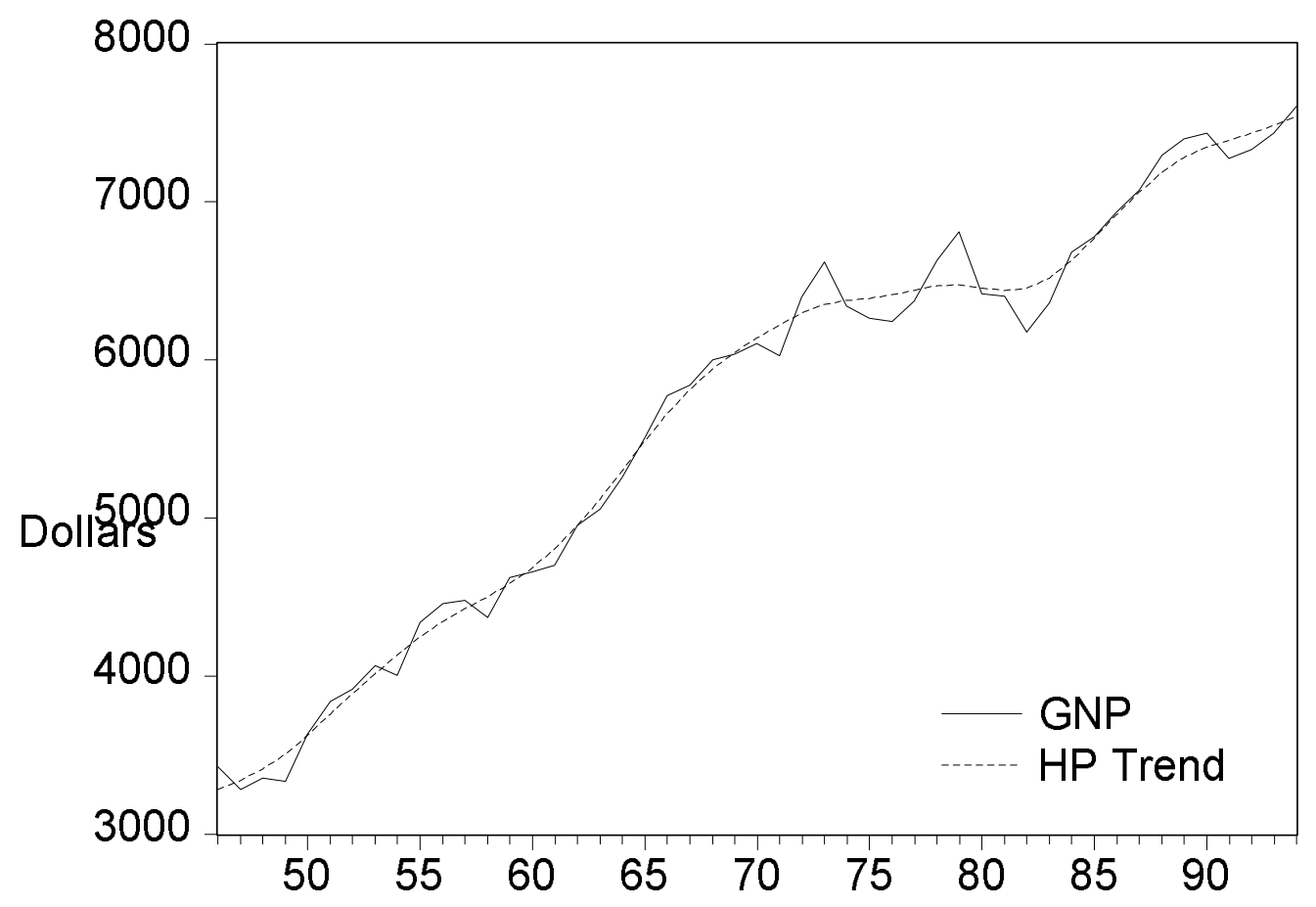


Technology Diffusion and Aggregate Dynamics

FIGURE 2

Diffusion of New Technology

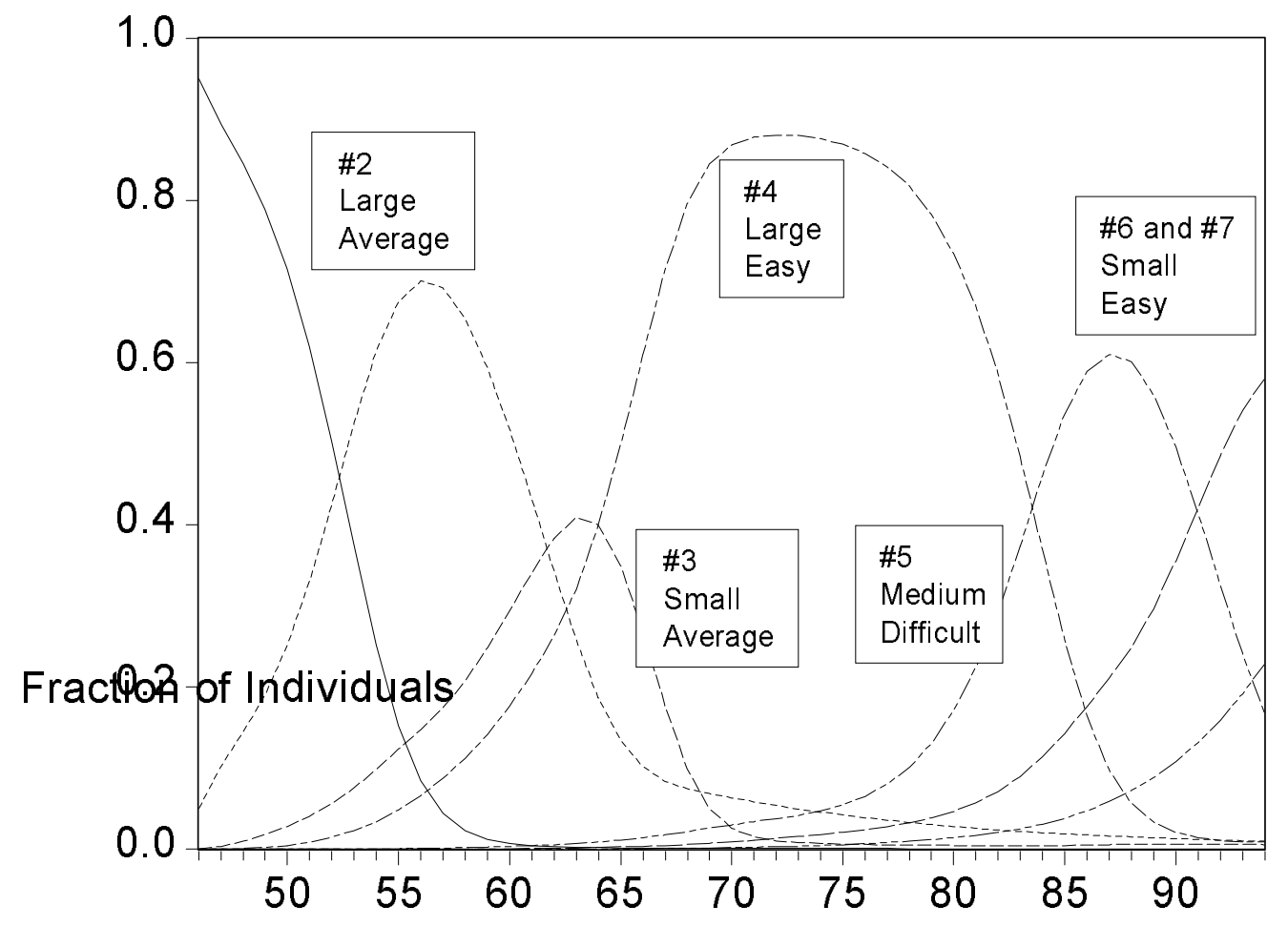


FIGURE 3

Predicted Technology Diffusion and Dispersion in Productivity Across Individuals

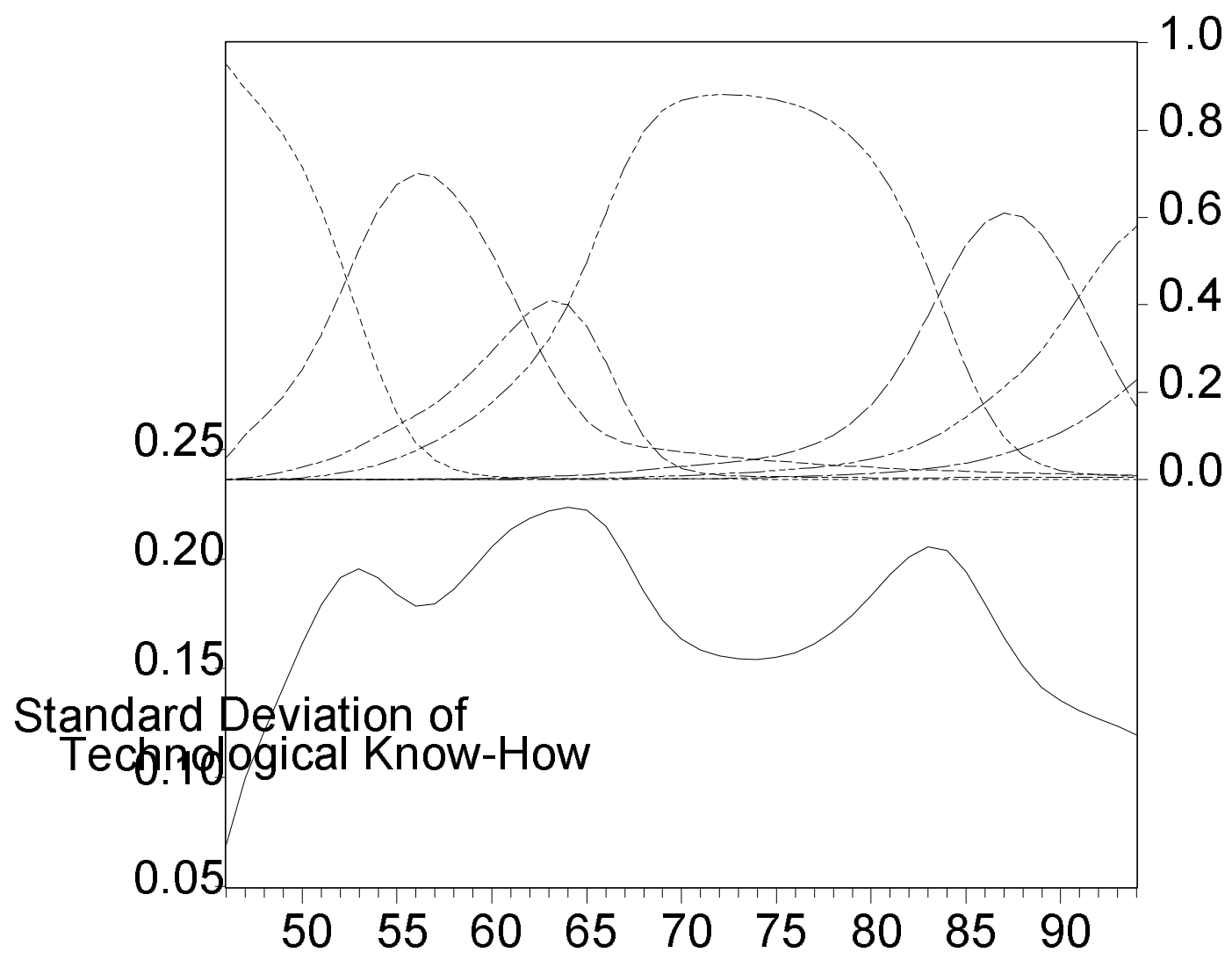


FIGURE 4

Opportunity for Technological Improvement

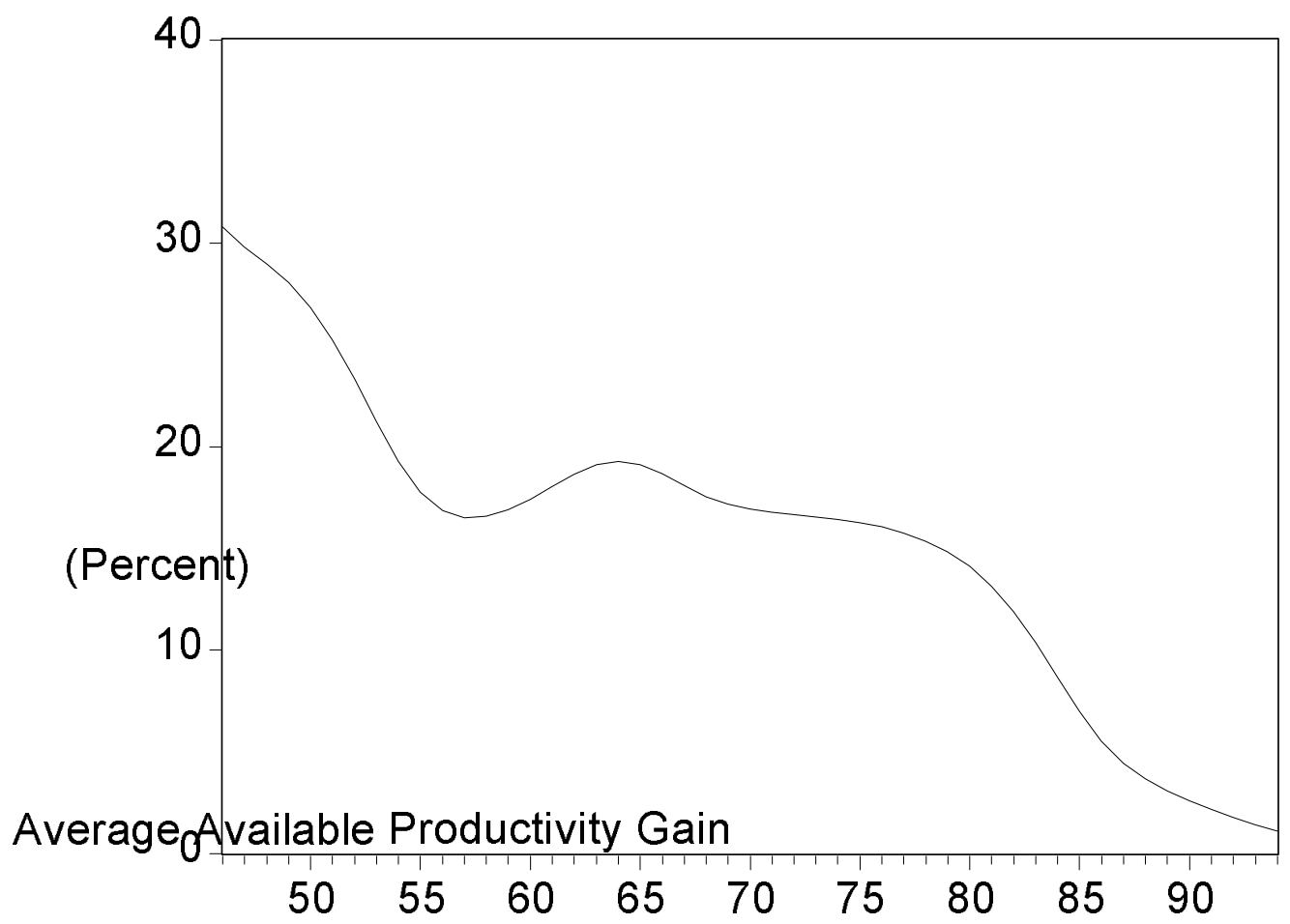


Technology Diffusion and Aggregate Dynamics

FIGURE 5

Real per Capita Output

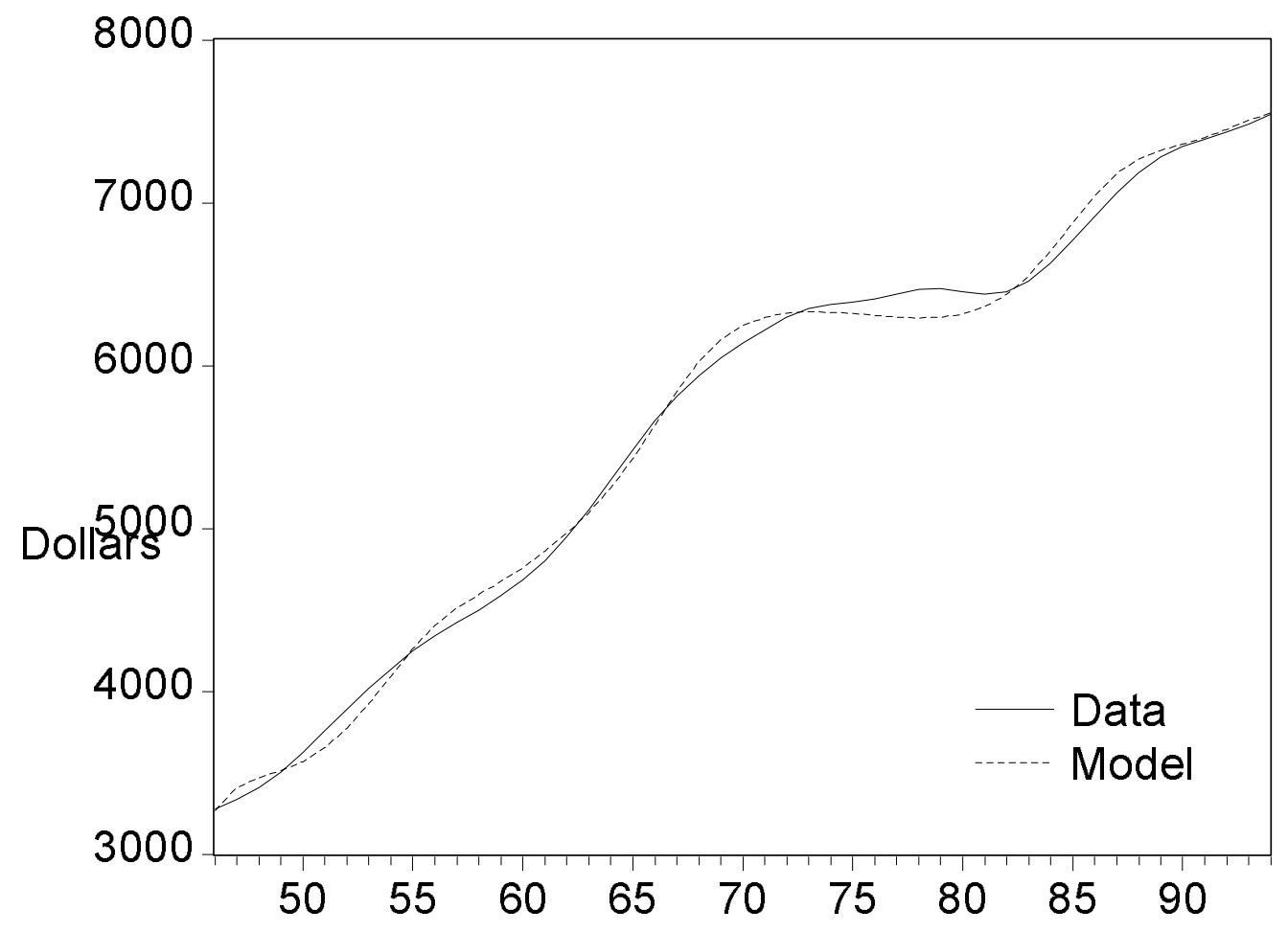


Technology Diffusion and Aggregate Dynamics

FIGURE 6

Real per Capita Output Growth

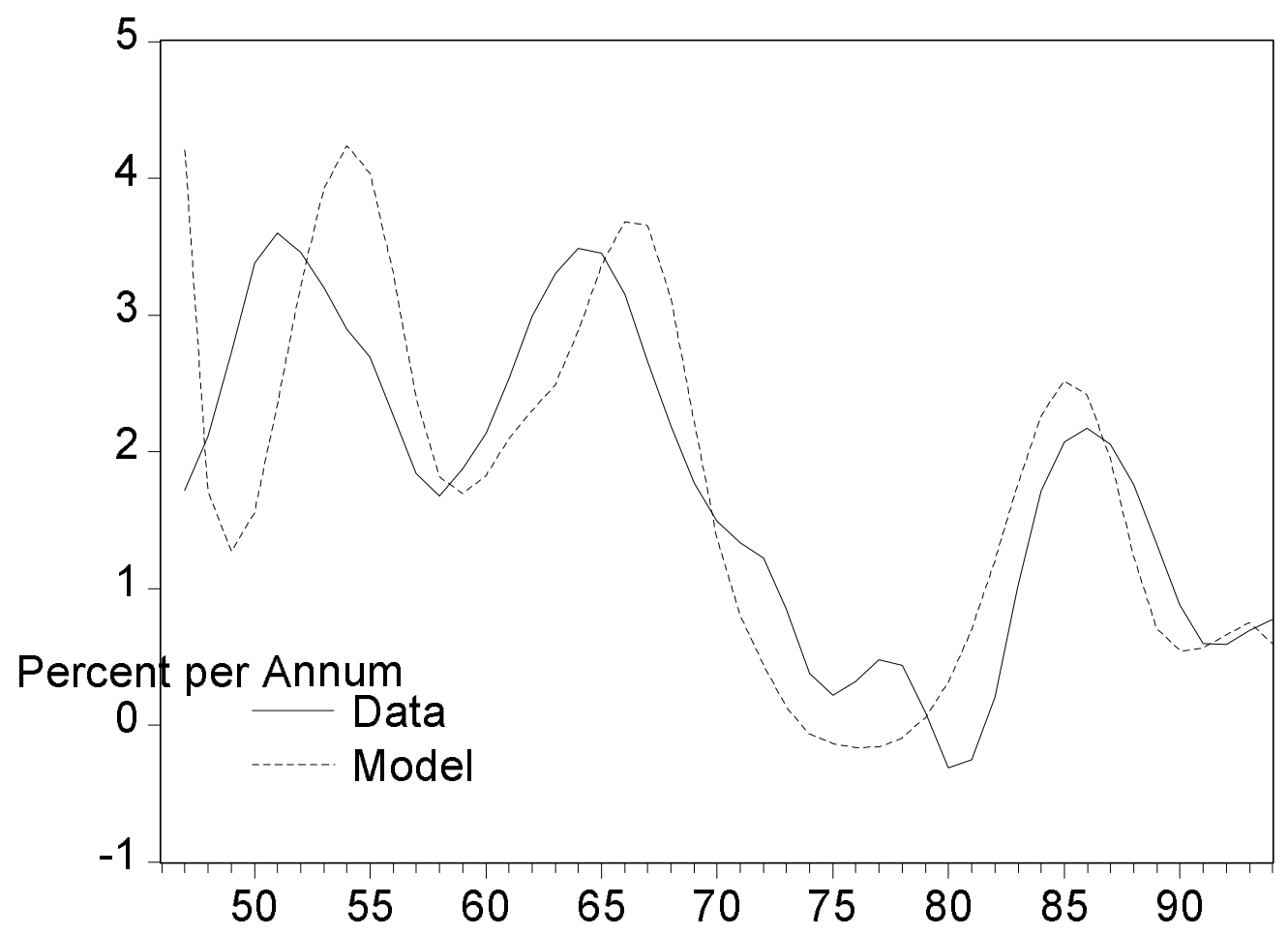


Technology Diffusion and Aggregate Dynamics

FIGURE 7

Predicted Technology Diffusion and Output Growth

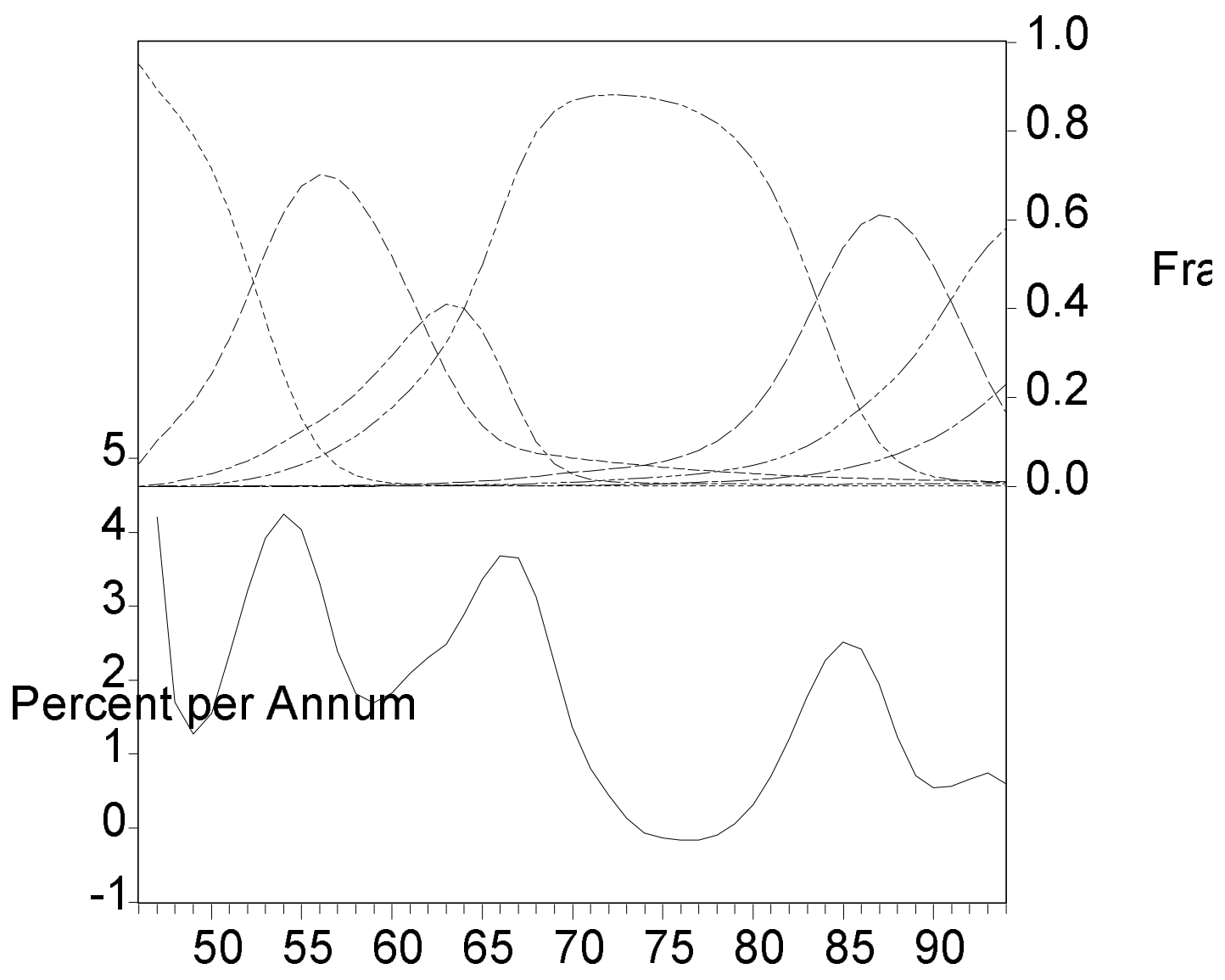


FIGURE 8

Predicted Technology Dispersion and Output Growth

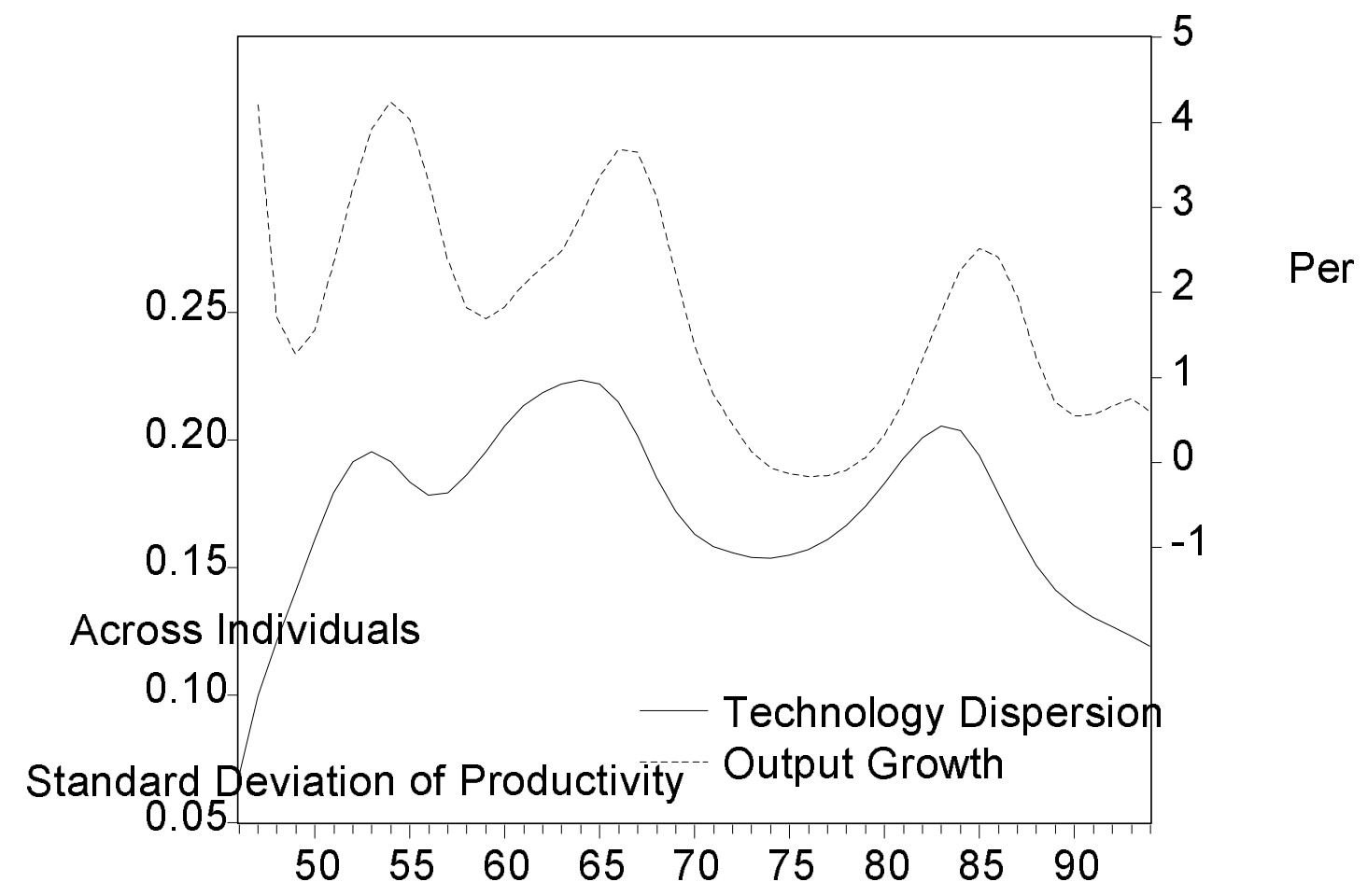


Technology Diffusion and Aggregate Dynamics

FIGURE 9

Consumption Expenditures

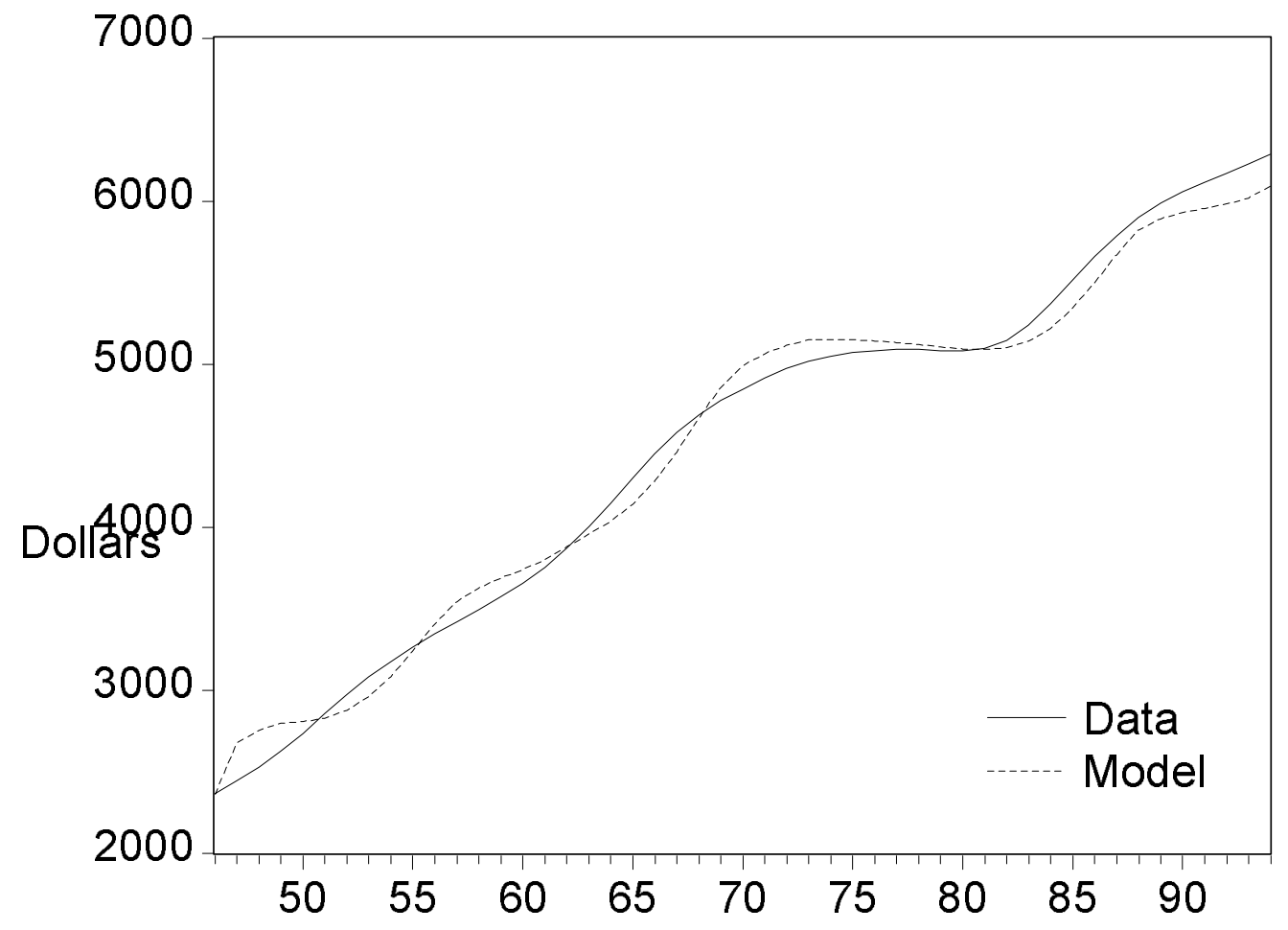


Technology Diffusion and Aggregate Dynamics

FIGURE 10

Wage Rate

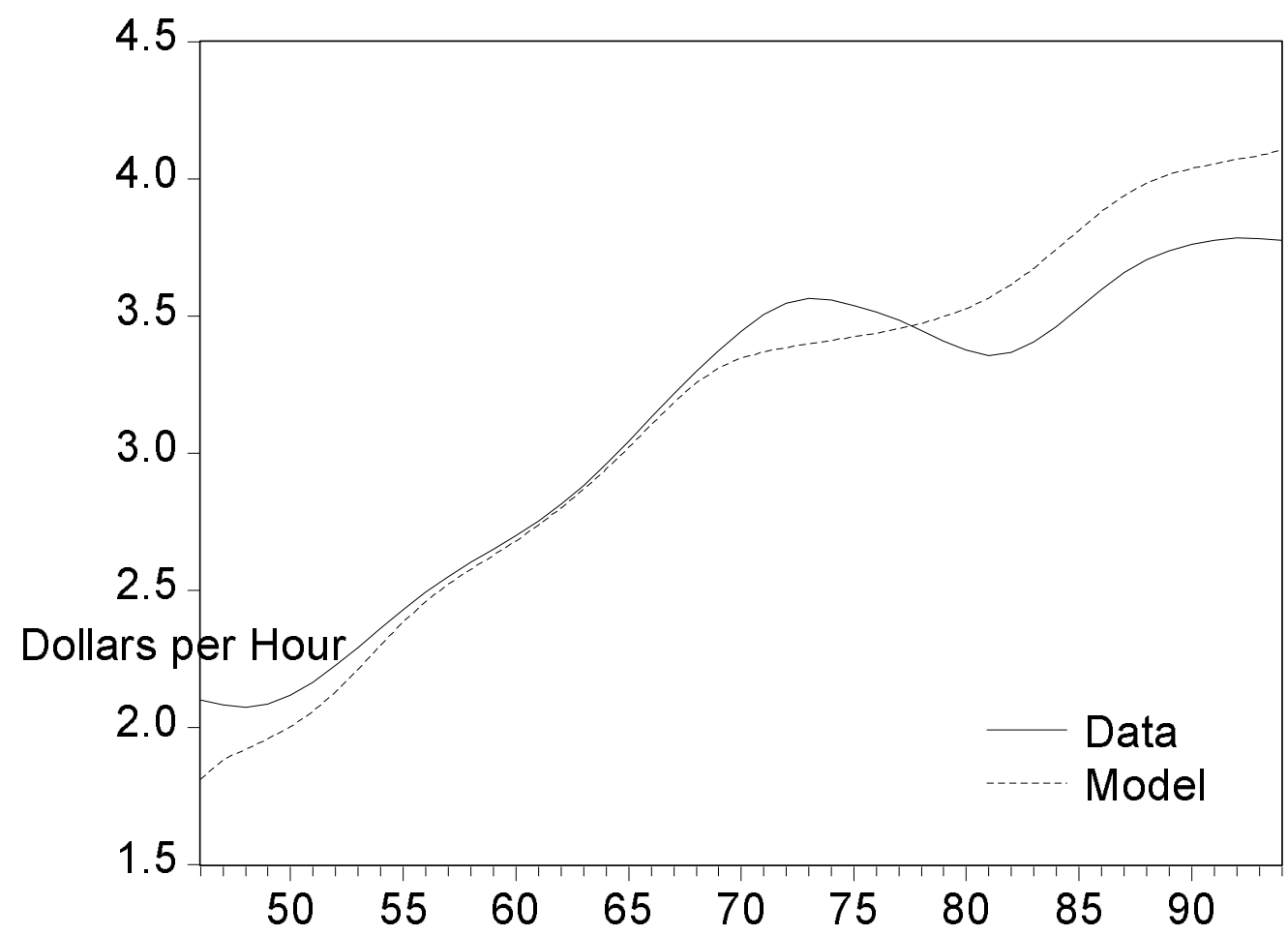


Technology Diffusion and Aggregate Dynamics

FIGURE 11

Capital Stock

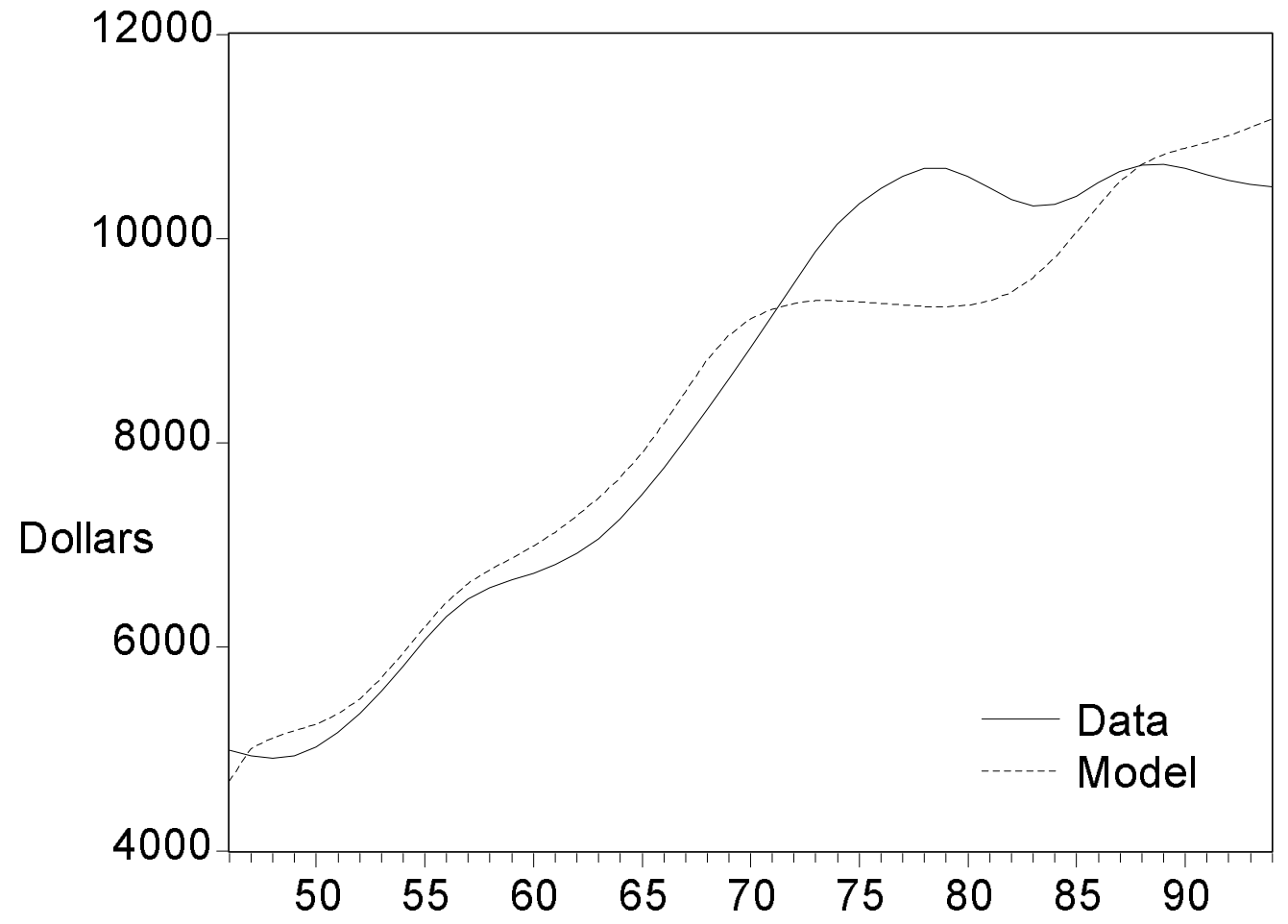


Technology Diffusion and Aggregate Dynamics

FIGURE 12

Aggregate Labor Input

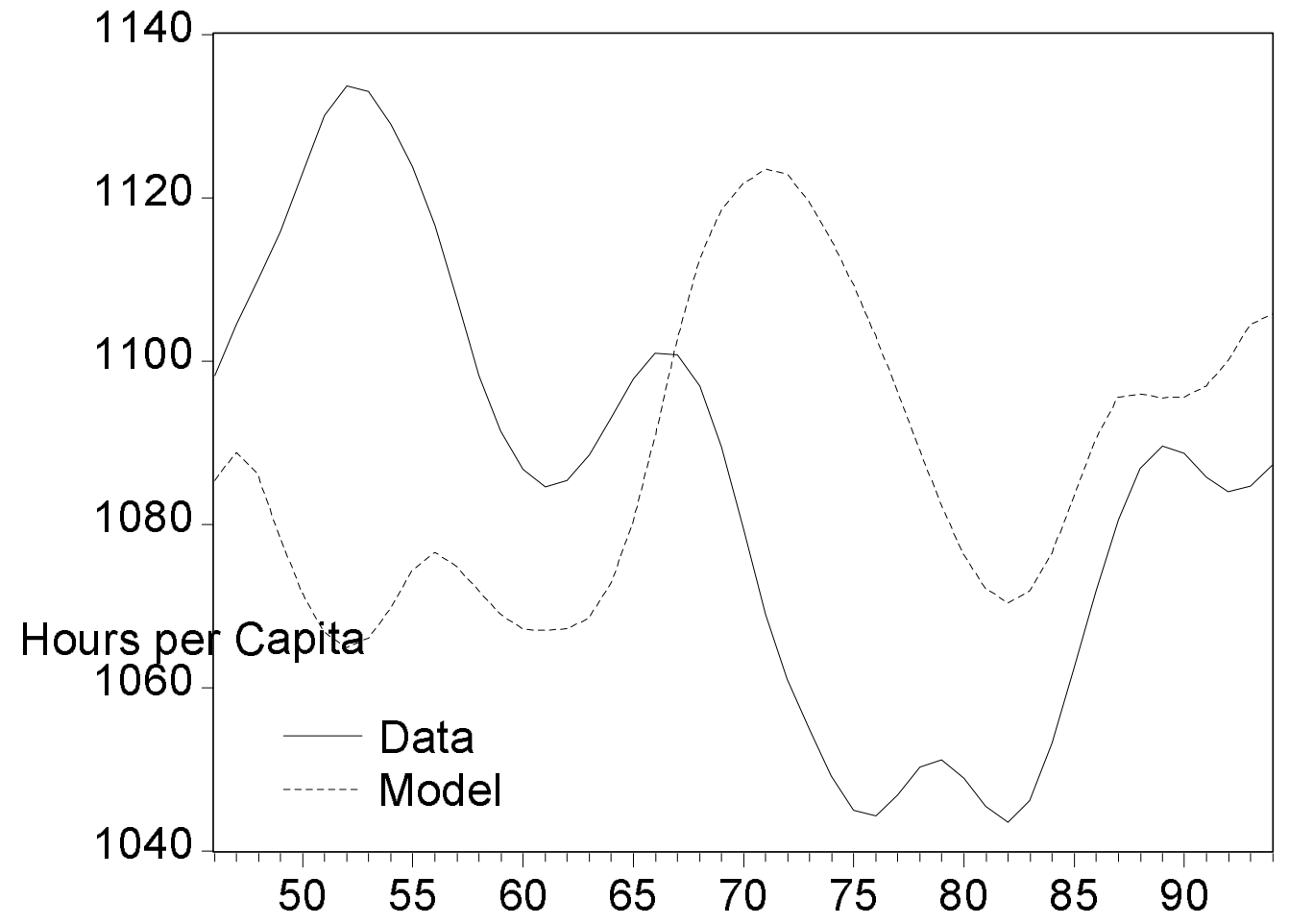


Technology Diffusion and Aggregate Dynamics

FIGURE 13

Predicted Technology Diffusion and Learning Effort

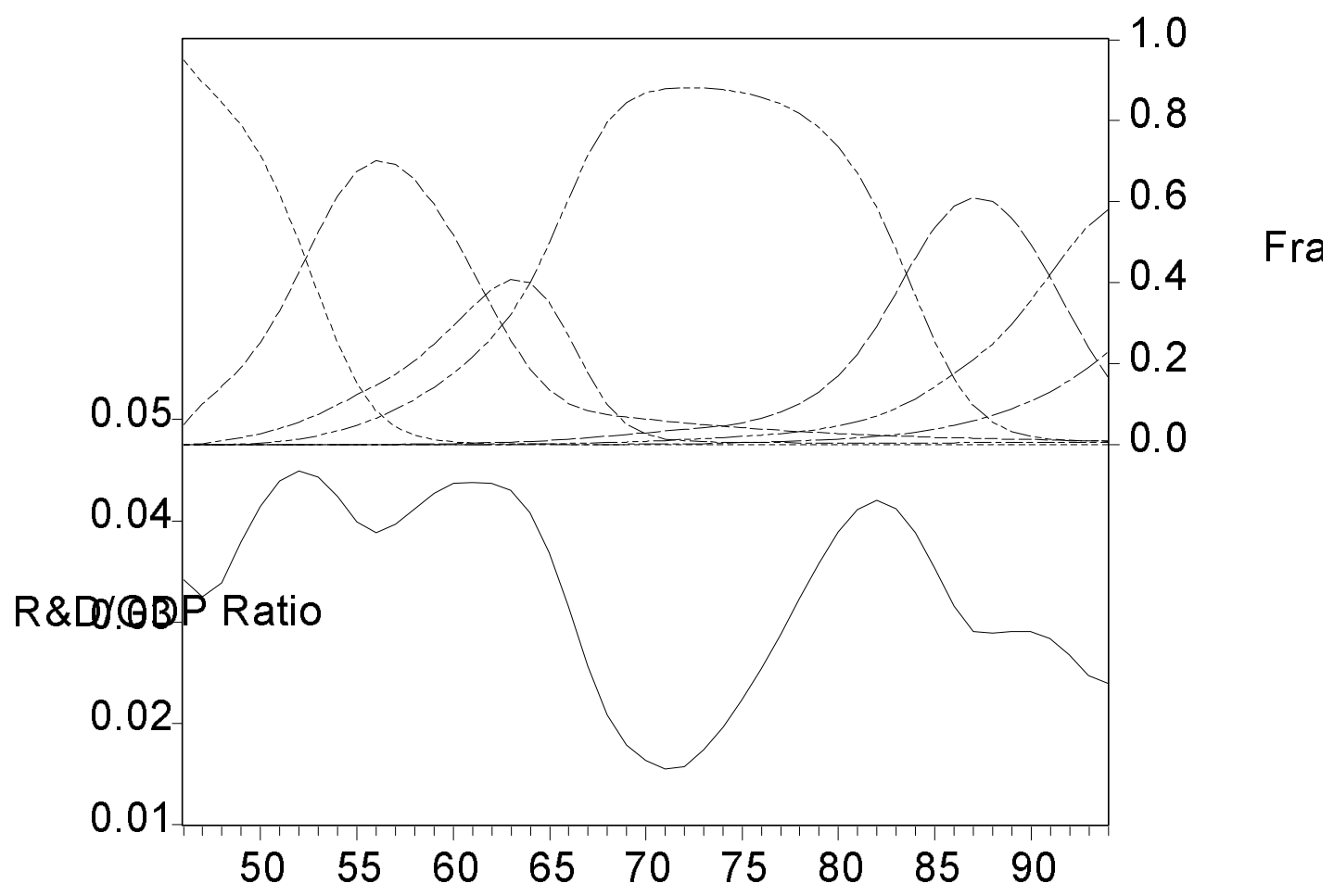


Technology Diffusion and Aggregate Dynamics

FIGURE 14

Predicted Growth in Output and R\&D

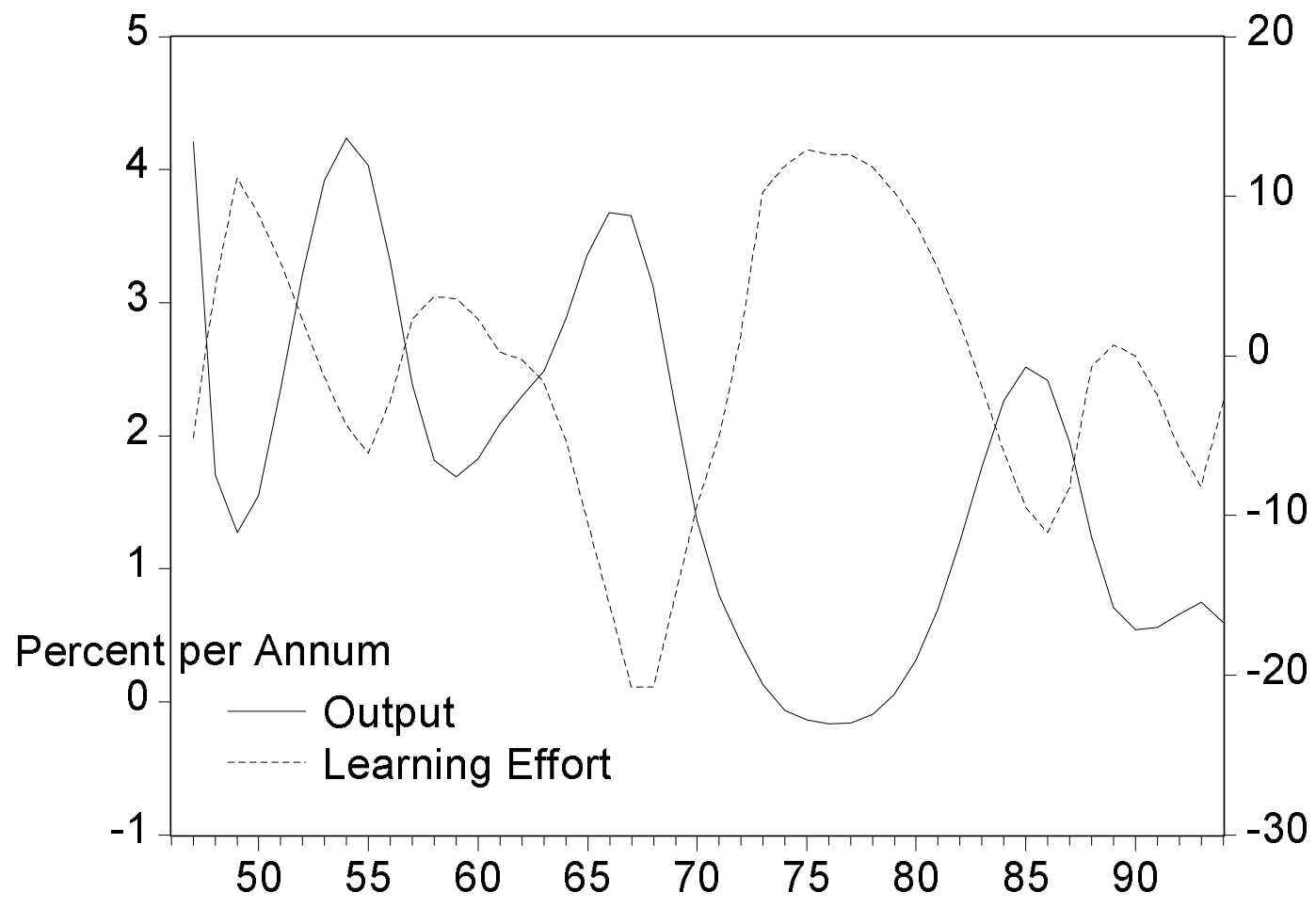


Technology Diffusion and Aggregate Dynamics

FIGURE 15

R\&D as Ratio of GNP

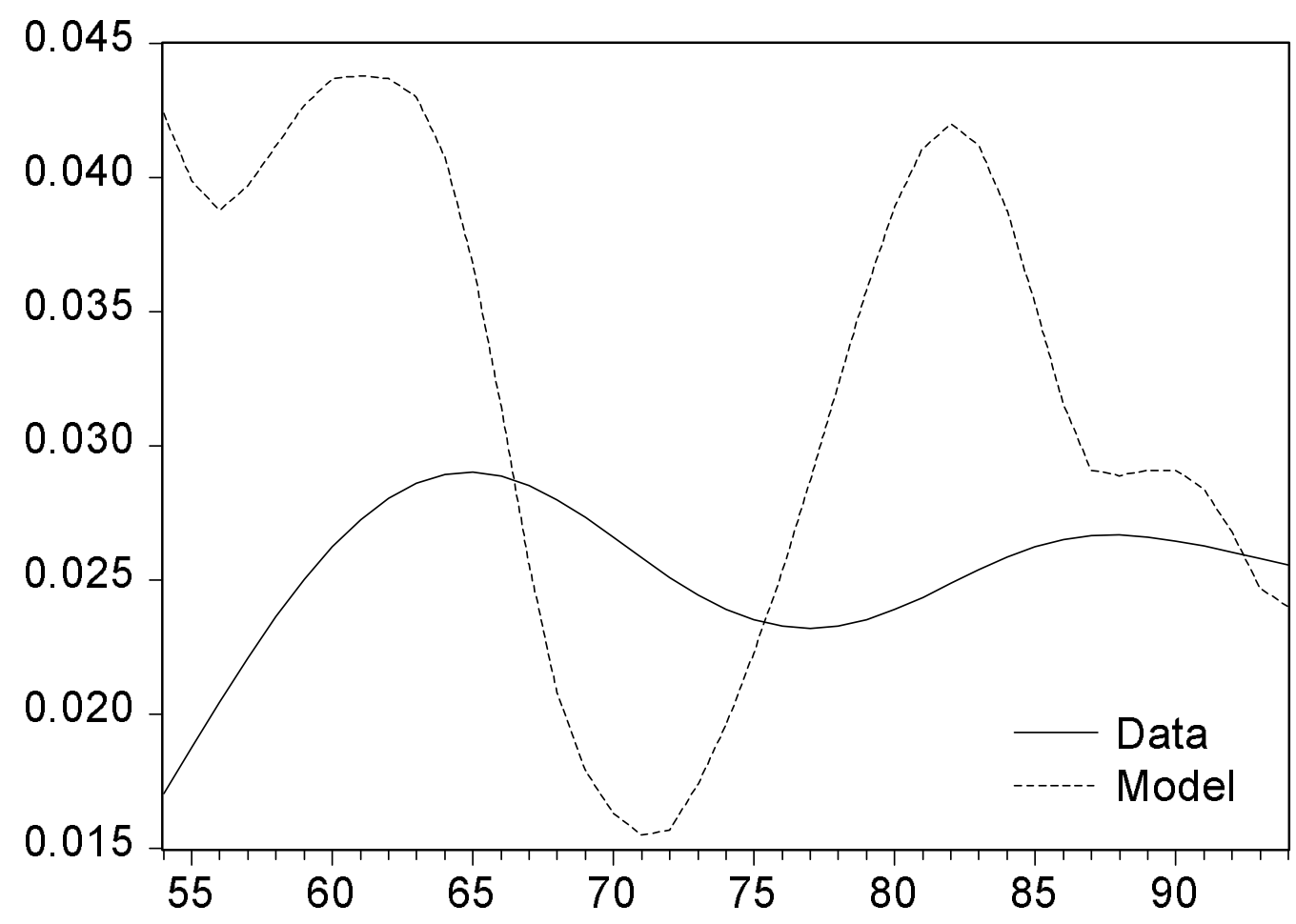


FIGURE 16

Predicted Technology Diffusion and Actual Invention Patents

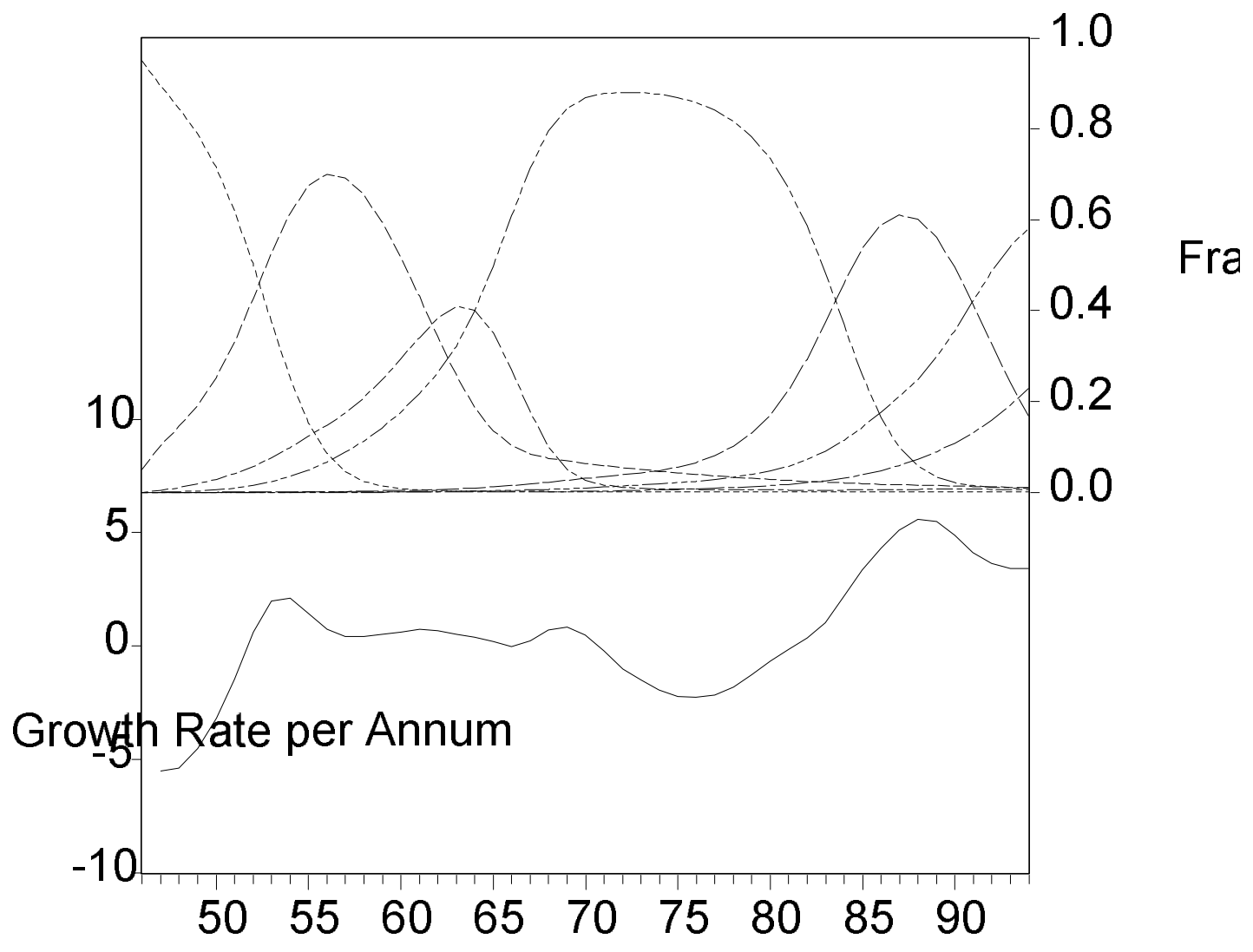


Technology Diffusion and Aggregate Dynamics

FIGURE 17

Predicted Technoloogy Diffusion and

Actual School Enrollment of Adults

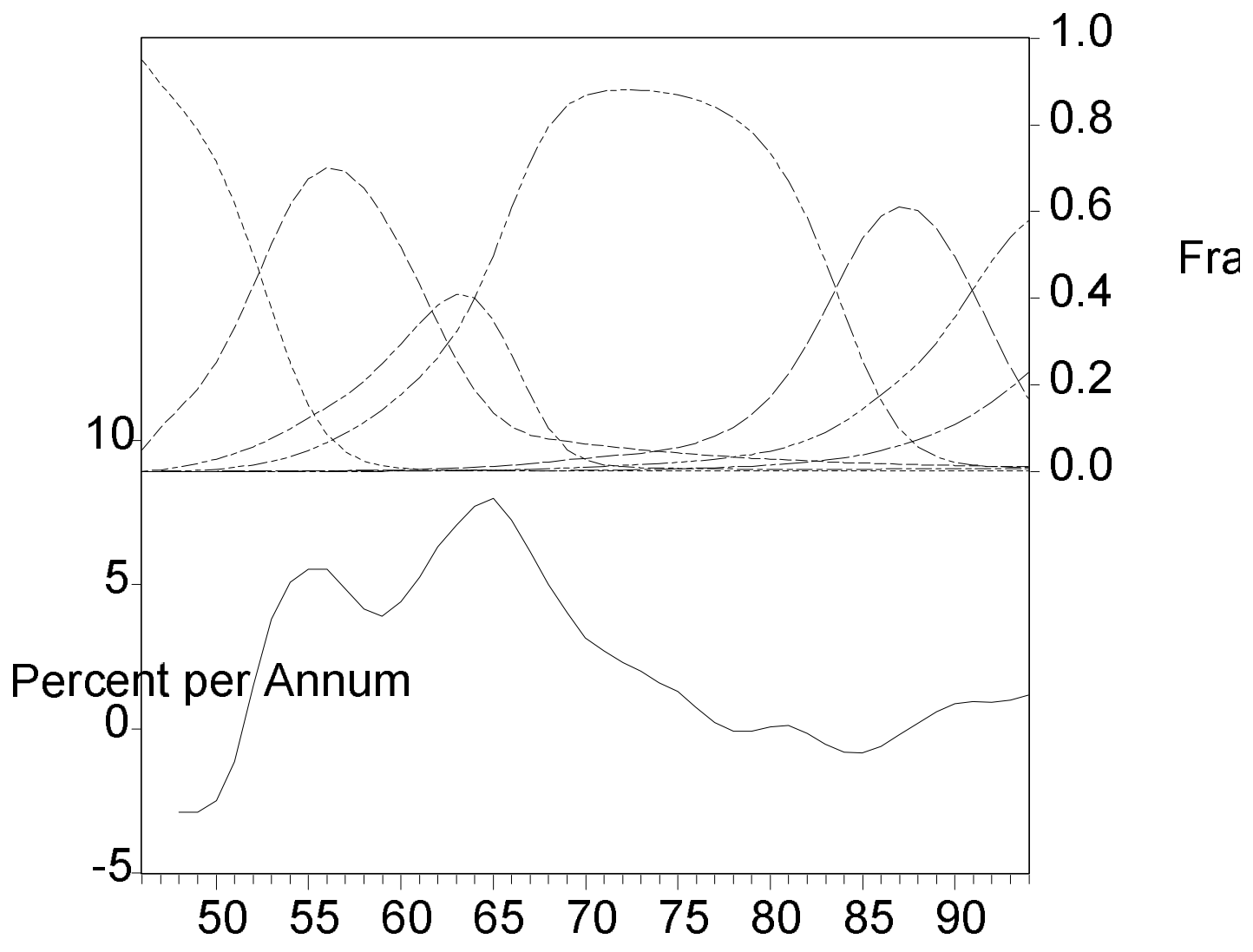


Technology Diffusion and Aggregate Dynamics

FIGURE 18

Growth in GNP and Applications

for Invention Patents

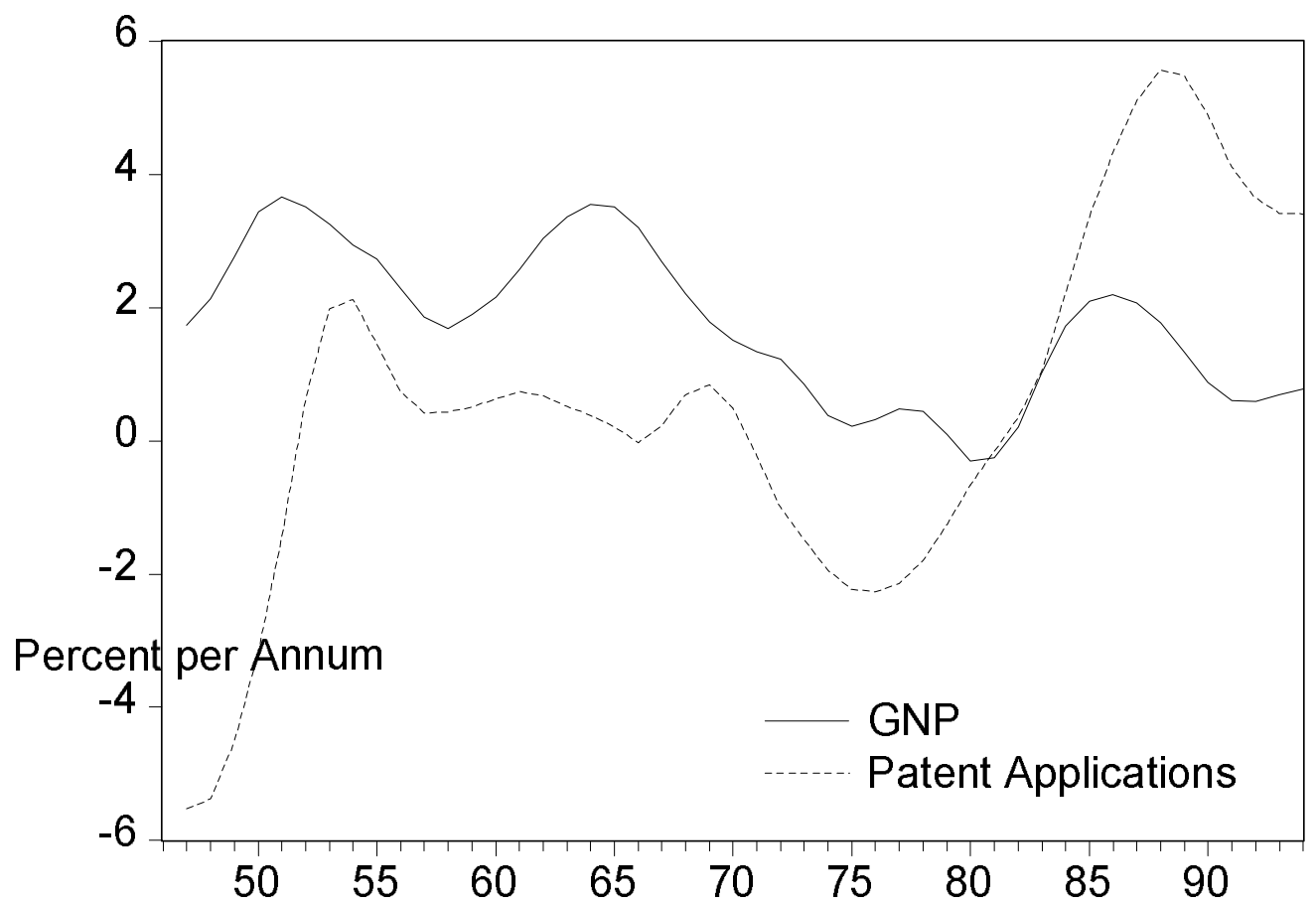


Technology Diffusion and Aggregate Dynamics

FIGURE 19

Growth in GNP and School

Enrollment for Adults

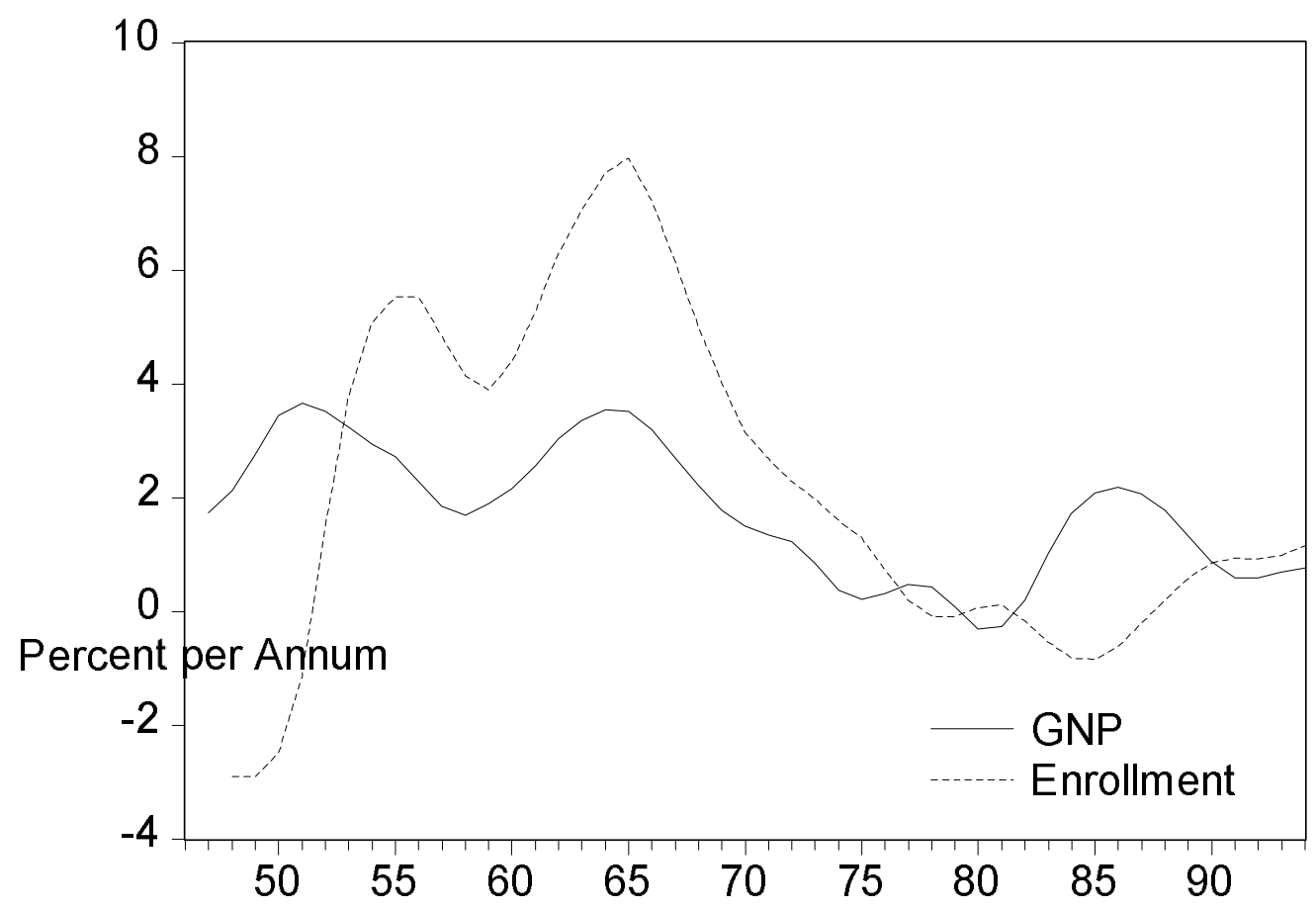


FIGURE 20

Shifting Composition of PhDs

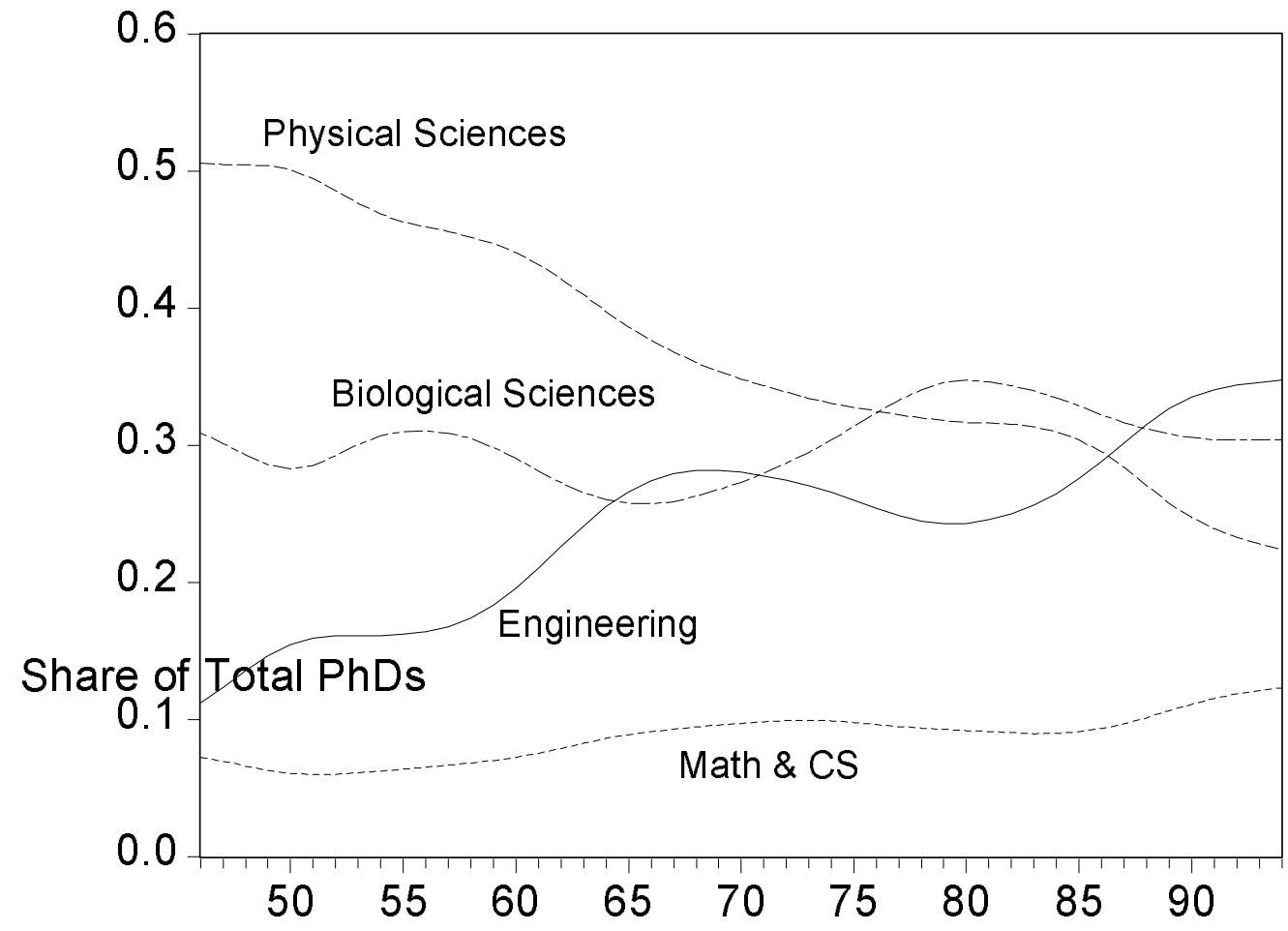


Technology Diffusion and Aggregate Dynamics

FIGURE 21

Growth in GNP and Engineer's

Share of PhDs

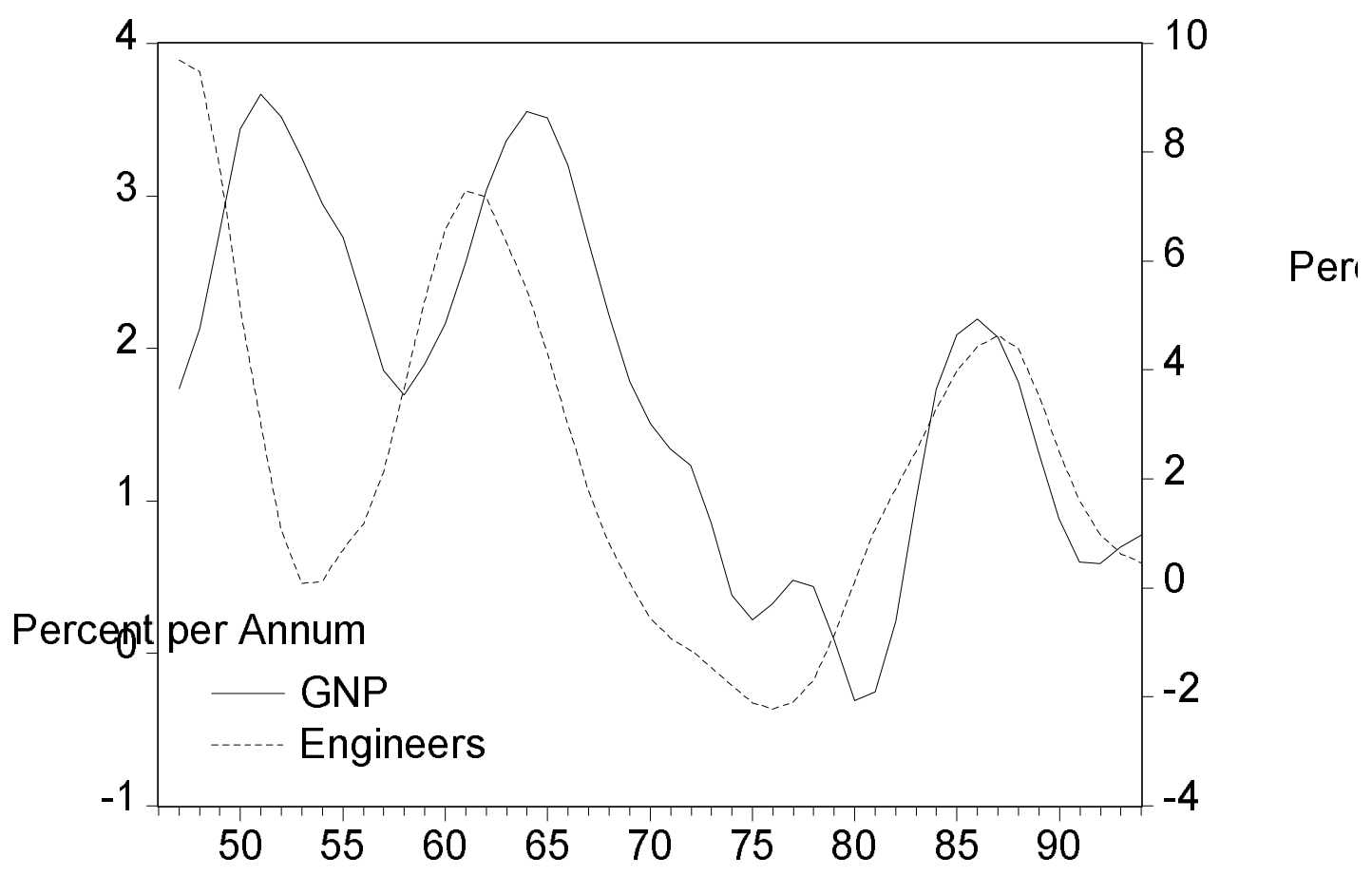




\section{Technology Diffusion and Aggregate Dynamics}

\section{References}

1. Aghion, Philippe and Peter Howitt (1992). "A Model of Growth Through Creative Destruction," Econometrica, 60: 323-352.

2. Andolfatto David and Glenn MacDonald (1991). "Endogenous Technological Change, Growth, and Aggregate Fluctuations," Working Paper: University of Western Ontario.

3. Bahk, Byong-Hyong and Michael Gort (1993). "Decomposing Learning by Doing in New Plants," Journal of Political Economy, 101: 561-83.

4. Bental, Benjamin and Dan Peled (1996). "The Accumulation of Wealth and the Cyclical Generation of New Technologies: A Search Theoretic Approach", International Economic Review, 37: 687-718.

5. Brady, R. (1961). Organization, Automation, and Society, University of California Press, Berkeley, California.

6. Bresnahan, T. and M. Trajtenberg (1995). "General Purpose Technologies: Engines of Growth?" Journal of Econometrics, 665: 83-108.

7. Campbell, Jeffrey (1997). "Entry, Exit, Embodied Technology, and Business Cycles," NBER Working Paper 5955.

8. Chari, V.V. and Hugo Hopenhayn (1991). "Vintage Human Capital," Journal of Political Economy, 99(6): 1142-1165.

9. Cheng, Leonard and Elias Dinopoulos (1991). "A Schumpeterian Model of Economic Growth and Fluctuations," Working Paper: University of Florida. 


\section{Technology Diffusion and Aggregate Dynamics}

10. Cooley, Thomas and Edward Prescott (1996). "Economic Growth and Business Cycles," in Cooley, T. F., (editor) (1996). Frontiers of Business Cycle Research, Princeton University Press, Princeton, New Jersey.

11. Ericson, Richard and Ariel Pakes (1995). "Markov-Perfect Industry Dynamics: A Framework for Empirical Work, Review of Economic Studies, 62: 53-82.

12. Gort, Michael and Stephen Klepper (1982). "Time Paths in the Diffusion of Product Innovations," Economic Journal, 92: 630-653.

13. Greenwood, Jeremy and Mehmet Yorukoglu (1997). "1974," Carnegie-Rochester Conference Series on Public Policy, 46: 49-96.

14. Hornstein, Andreas and Per Krusell (1996). "Can Technology Improvements Cause Productivity Slowdowns?" NBER Macroeconomics Annual.

15. Jovanovic, Boyan and Saul Lach (1997). "Product Innovation and the Business Cycle," International Economic Review, 38(1): 3-22.

16. Jovanovic, Boyan and Rob Rafael (1990). "Long Waves and Short Waves: Growth Through Intensive and Extensive Search," Econometrica, 58: 1391-1409.

17. Jovanovic, Boyan and Glenn MacDonald (1994). "Competitive Diffusion," Journal of Political Economy, 102(1): 24-52.

18. Justman Moshe (1997). "Growth Through Innovation: A Schumpeterian Perspective," Working Paper: Ben-Gurion University.

19. Kydland, Finn (1996). "Business Cycles and Aggregte Labor Market Fluctuations," 


\section{Technology Diffusion and Aggregate Dynamics}

in Cooley, T. F., (editor) (1996). Frontiers of Business Cycle Research, Princeton University Press, Princeton, New Jersey.

20. Lippi, Marco and Lucrenza Reichlin (1994). "Diffusion of Technical Change and the Decomposition of Output into Trend and Cycle," Review of Economic Studies, 61: 1930.

21. Lynn, F. (1966). An Investigation of the Rate of Development and Diffusion of Technology in Our Modern Industrial Society, in the National Commission on Technology, Automation and Economic Progress, U.S.G.P.O., Washington, D.C.

22. Mansfield, E., J. Rapoport, A. Romeo, E. Villani, S. Wagner, and F. Husic (1977). The Production and Application of New Industrial Technology, W.W. Norton \& Co., New York.

23. Prescott, Edward (1986). "Theory Ahead of Measurement," Federal Reserve Bank of Minneapolis Quarterly Review, 9-22.

24. Rosenberg, Nathan (1972). Technology and American Economic Growth, Harper \& Row.

25. Schumpeter, Joseph (1939). Business Cycles: A Theoretical, Historical and Statistical Analysis of the Capitalist Process, McGraw-Hill, New York.

26. Schumpeter, Joseph (1942). "Capitalism, Socialism and Democracy," Harper \& Row. 


\section{Technology Diffusion and Aggregate Dynamics}

\section{Data Appendix}

\subsection{General}

All data are taken from one of:

[a] U.S. Bureau of the Census, Historical Statistics of the United States, Colonial Times to 1970, Bicentennial Edition, Parts 1 and 2, Washington, D.C., 1975.

[b] U.S. Bureau of the Census, Statistical Abstract of the United States, Various issues, Washington, D.C.

[c] U.S. Department of Commerce, Bureau of Economic Analysis, Fixed Reproducible Tangible Wealth in the United States, 1925-85, U.S. Government Printing Office, June 1987, and its update May 1997 Survey of Current Business.

\subsection{Base Series}

All data used are calculated from the following series:

Population $(N)$ - Total non-institutional population over the age of 16 , including armed forces overseas. Sources: 1940-70, series A39 of [a]; 1974-88, [b]. The 1971-73 figures are geometric interpolations of the 1970 and 1974 figures.

Consumption $(C)$ - Personal consumption expenditures, in nominal billions. Source: 1940-70, series G416 of [a]; 1971-94, [b].

Price Level $(P)$ - Consumer price index, 1967=100. Source: 1940-70, Series E135 of [a]; 1971-94, [b].

Output $(Y)$ - Gross national product. Source: 1940-70, Series F1 of [a]; 1971-94, [b]. 


\section{Technology Diffusion and Aggregate Dynamics}

Government Expenditures $(G)$ - Purchases of goods and services by all levels of government. Source: 1940-50 even years, and 1952-70, Series F6 of [a]; 1971-94, [b].

Government Capital Outlays $(G C)$ - Capital outlays by all levels of government. Source: 1952-70, series Y523 of [a]; 1971-94, [b]. Data for 1940-51 were constructed as follows: Let $F_{t}=$ total federal government outlays in year $t$ and $R_{t}=$ nominal interest rate in year $t$ (see [8] below). Using the data available for 1952-86, the OLS regression:

$$
\ln \left(G C_{t} / G_{t}\right)=-0.588+0.766 \ln \left(F_{t} / G_{t}\right)+0.009\left(R_{t}-100\left[\frac{P_{t+1}-P_{t}}{P_{t}}\right]\right)-0.028 t
$$

was computed $\left(R^{2}=0.929\right)$ and used to forecast $\ln \left(G C_{t} / G_{t}\right)$ for 1940-51.

Capital Stock $(K)$ - Net stock of fixed non-residential structures and equipment, public and private, current cost valuation method. Source: 1940-94, [c].

Weekly Hours $(H)$ - An employment weighted average of average weekly hours in all manufacturing, contract construction, wholesale trade, retail trade, finance, insurance and real estate. Source: (i) Hours. 1940-70, series D803, D878, D881 and D890 of [a]; 1971-94 [b]. Finance, insurance and real estate is included only from 1947 onwards. (ii) Employment. 1940-70, Series D129, D130, D135, D136, and D137; 1971-94 [b].

Labor Force $(L)$ - Total employed labor force, age 16 and over, including armed forces. Sources: 1940-70, series D1, D8, D12 and D18 of [a]; 1971-94, [b]. For 1947-70, the employed labor force is the difference between the total labor force (D12) and the unemployed (D18). For 1940-46, the figure is the employed labor force 14 and over (D1-D8), multiplied by the population 16 and over to the population 14 and over.

Annual Earnings $(E)$ - Total Earnings, wages and salaries; includes self-employment and 
military earnings. Source: 1940-70, series H57 of [a]; 1971-94, [b].

\subsection{Constructed Series}

Real per capita consumption: $(C+G-G C) /(P N)$

Real per capita output: $Y /(P N)$

Annual hours per capita: $50 \mathrm{HL} / \mathrm{N}$

Capital stock per capita: $\quad K /(P N)$

Real hourly wage: $E /(50 H L P)$ 